\title{
INFLUENCE OF LONG CHAIN BRANCHING ON FIBER DIAMETER DISTRIBUTION FOR POLYPROPYLENE NONWOVENS PRODUCED BY MELT BLOWN PROCESS
}

\author{
Jiri Drabek and Martin Zatloukal* \\ Polymer Centre, Faculty of Technology, Tomas Bata University in Zlín, \\ Vavrečkova 275, 76001 Zlín, Czech Republic
}

Keywords: Polymer melt, rheology, melt blown, isotactic polypropylene, linear and branched polypropylene.

*Corresponding author: mzatloukal@utb.cz 


\begin{abstract}
\end{abstract}
In this work, linear isotactic polypropylene (L-PP) and long-chain branched polypropylene miscible blend (LCB-PP), both having comparable weight average molecular weight, zero-shear viscosity and polydispersity index, were used to produce nonwovens via melt blown technology in order to understand role of long chain branching on the fiber diameter distribution. Basic morphological characteristics of produced nonwoven samples have been determined using digital image analysis of SEM images considering different magnifications to capture nanofibers as well as microfibers. At the same air flow rate, polymer flow rate, and temperature the average fiber diameters were the same, $1.6 \mu \mathrm{m}$, but the coefficient of variation, $C V$, was greater for the linear PP than for the blend. Material elasticity was assessed by reptation-mode relaxation time, $\lambda$, determined by fitting of deformation rate dependent shear viscosity by Cross and Carreau-Yasuda models as well as via fitting of frequency dependent loss and storage moduli master curve by a two-mode Maxwell model. It was found that $\lambda$ is higher for LCB-PP in comparison with L-PP and the Cross model gives a meaningful relaxation time while the Carreau-Yasuda model does not despite giving a better numerical fit. Extensional rheology was assessed by the strain rate dependent uniaxial extensional viscosity (estimated from the entrance pressure drop using the Gibson method). The infinite shear to zero-shear shear viscosity ratio $\eta_{\infty} / \eta_{0}$ ratio (obtained directly from the shear viscosity data measured in a very wide shear rate range) was shown to be proportional to the maximum normalized extensional viscosity at very high extensional strain rates, $\eta_{E, \alpha}\left(3 \eta_{0}\right) . \eta_{\infty} / \eta_{0}$ was related to temperature and basic molecular characteristics of given polymers via simple equation. It was observed that extensional viscosity for both samples firstly decreases with increased extensional strain rate to its minimum value at $200000-4000001 / \mathrm{s}$, and then increases to plateau value, $\eta_{E, \infty}$ (corresponding to the maximum chain stretch) at about $2 \cdot 10^{6} 1 / \mathrm{s}$. 
At low deformation rates, extensional viscosity is higher for LCB-PP in comparison with L-PP, but the trend is switched at very high deformation rates; $\eta_{E, \infty}$ (and also $\eta_{E, \infty} / 3 \eta_{0}$ ) becomes lower for LCB-PP in comparison with L-PP. These results suggest that high stability of LCB-PP blend can be explained by its higher stretchability at very high deformation rates (occurring at the die exit where an intensive fiber attenuation takes the place) and its lower stretchability at medium and low deformation rates, at which melt/air inertia driven bending instability called whipping occurs. 


\section{INTRODUCTION}

Melt blown technology is a process, in which polymer melt is pushed through a spinnerette die containing hundreds or thousands small orifices (typically in the range of $9-100$ per inch) [1 - 4] with consequent stretching of formed fibers by hot air, which can reach speed of the sound [5]. Sketch of the melt blown line is provided in Figure 1. Produced fibers, typically with average fiber diameters about $1-2 \mu \mathrm{m}[2,6-8]$, are collected on the suitable collector in the form of nonwoven textile, which is commonly used in area of medical equipment such us surgical face mask and gowns, drapes, filtration (air or liquid), battery separators, sorbents and wipes, protective overalls, face mask, hygiene (diapers, nappies, towels), biosensors, scaffolds for tissue engineering and many other areas $[7,9,10]$. Polypropylene is the most frequently utilized material in this process for its low cost, ease of processing, good mechanical properties, and chemical inertness [11 - 13]. There is number of unwanted flow phenomena, which significantly increases nonuniformity of produced polymeric fibers and/or reduces the processing window in this technology, namely: whipping-like motion of fibers due to turbulent air flow field [8, $14-24]$, fiber breakup [8, 25] (leading to melt spraying [8, 19, 22, 23, 26], formation of very short fibers flies $[2,8,23,26-29]$ and generation of small isolated spherical particles [8]), jam-connecting two or more individual fibers together increasing resulting fiber diameter considerably, [23], die drool - unwanted accumulation of material at the die exit [30], secondary flow - occurrence of vortexes inside the die reducing the flow stability [31] and shots - creation of holes in the produced nonwoven textile $[6,8,32-35]$.

It was found that fiber diameter distribution is well described by log-normal function [8, 36 - 38]. There is very little knowledge on the role of polymer chain structure and rheology on the 
fiber diameter distribution, especially for PPs. Nayak et al. [7] have shown that injection of air and water into the vent port of the extruder decreased shear viscosity and molecular weight of two polypropylenes (having originaly $\mathrm{M}_{\mathrm{w}}=100875 \mathrm{~g} / \mathrm{mol}$ and $\mathrm{M}_{\mathrm{w}}=77590 \mathrm{~g} / \mathrm{mol}$ ) by $61.8 \%-63.4$ $\%$ and $56.6 \%-58.8 \%$, respectively, causing reduction in fiber diameter, down to $438-755 \mathrm{~nm}$. The role of Newtonian viscosity, $\eta_{0}$, and elasticity (captured via the longest melt relaxation time, $\lambda$ ) on diameter distribution of melt blown fibers was systematically studied for binary polystyrene blends (comprised of low molecular weight PS and different levels of high molecular weight PS) in [36] utilizing a single-hole melt blowing die and the same operating conditions (hole diameter $=0.2 \mathrm{~mm}, \mathrm{~T} \sim 180^{\circ} \mathrm{C}$ ). It has been found that firstly, decrease in $\eta_{0}$ (i.e. in the molecular weight) decreased average fiber diameter with little effect on coefficient of variation, $C V$, and secondly, if $\lambda$ became higher than a threshold value, $C V$ was reducing while simultaneously, average fiber diameter was increasing. These findings have been confirmed theoretically by Zhou C., [39] based on 1D slender-jet approach utilizing a Giesekus (or PTT) constitutive equation and linear stability analysis. The authors also mentioned that "PS is not commonly used for melt blown nonwoven products, especially at the molecular weights considered here, due to poor solvent and thermal resistance and due to brittleness" [36]. This gives rise to the question, whether the obtained conclusions for binary PS blends are also valid for industrially important melt blown polymers such as PPs (linear and branched), multi-hole melt blowing dies and different processing conditions. Moreover, the melt elasticity was correlated with the linear viscoelasticity property only (i.e. with the longest relaxation time) although fiber attenuation in melt blowing is a nonlinear process associated with very high extensional strain rates $\left(\sim 10^{6} \mathrm{~s}^{-1}\right)$. The authors justified this utilized simplification by the statement that "currently there is no extensional method available to quantify the non-linear rheological behavior at these high rates" [36]. Thus, utilization of 
methodologies and parameters allowing to determine extensional rheology of melt blown polymers at very high deformation rates can be considered as the key step to further explore understanding of polymeric nanofibers formation by the melt blown technology.

In order to understand role of long chain branching in PPs on elasticity, high extensional rate rheology and melt blown stability, well characterized linear polypropylene (L-PP) and longchain branched polypropylene (LCB-PP) blend (both having comparable molecular weight, polydisperzity index a zero-shear viscosity) were used to produce nonwovens with comparable average fiber diameter on multi-hole Reifenhäuser Reicofil pilot plant melt blown line at different Die-to-Colector Distances (DCDs).

\section{EXPERIMENTAL}

\section{Materials}

In this work, linear isotactic PP (L-PP, 76k, Borflow HL504FB) and PP miscible blend (containing 30wt\% of high molecular weight branched PP Daploy WB180HMS (LCB-PP, 247k) in low molecular weight linear PP Borflow HL512FB (L-PP, 56k)) were used. These samples, which have been provided by Borealis Polyolefine company (Linz, Austria), were carefully characterized via an Advanced Rheometric Expansion System (ARES, 2000 model, Rheometrics Scientific, USA) using parallel plate geometry, a Rosand RH7-2 twin bore capillary rheometer and a high accuracy Fanuc Roboshot S-2000i electric high-speed injection molding machine using an instrumented rheometric capillary die nozzle and high temperature gel permeation chromatography in [40, 41]. For high-shear rheology, a capillary die of $8 \mathrm{~mm}$ length and diameter $0.5 \mathrm{~mm}$ as well as an orifice die of the same diameter were used to enable Bagley and Weissenberg-Rabinowitsch 
corrections. Low shear rate viscosity data were measured with $25 \mathrm{~mm}$ parallel plates utilizing torque transducer $2 \mathrm{~K}$ FRTN1 with a $2 \mu \mathrm{Nm}$ low resolution limit. The aluminium bottom plate with the overflow channel was used to prevent polymer melt leakage flow out of the geometry. Due to extremely low viscosities of tested PPs it was only possible to measure viscosity without significant scattered data only above about 1 1/s. Basic molecular characteristics; first, $\eta_{0}$, and secondary, $\eta_{\infty}$, Newtonian plateau viscosities; zero-shear rate, $E_{0}$, and infinite, $E_{\infty}$, flow activation energies for all utilized melt blown polypropylene samples are summarized in Tab. 1 and Figure 2. Although samples have comparable weight average molecular weights $\left(\mathrm{M}_{\mathrm{w}}=76-78 \mathrm{~kg} / \mathrm{mol}\right)$, polydispersity $(4.41-4.50)$ by gel permeation chromatography and $\eta_{0}\left(\mathrm{~T}=230^{\circ} \mathrm{C}\right)=22.8-24.5$ $\mathrm{Pa} \cdot \mathrm{s}, \mathrm{LCB}-\mathrm{PP}$ blend is more elastic due to presence of the branched high molecular weight PP component, which is visible in Figure 2 as the high molecular weight tail. Note that LCB-PP sample has star-like structure [42 - 48] and L-PP/LCB-PP systems are miscible for blends containing up to $50 \mathrm{wt} \%$ LCB-PP [46, $49-52]$.

In order to determine characteristic (reptation-mode) relaxation time, $\lambda$, for material elasticity assessment, two different methodologies were used. In the first method, flow curves for given samples were fitted by Cross, Eq.1, and Carreau-Yasuda, Eq.2, models

$$
\begin{aligned}
& \eta(\dot{\gamma})=\eta_{\infty}+\frac{\eta_{0}-\eta_{\infty}}{1+(\lambda \dot{\gamma})^{a}} \\
& \eta(\dot{\gamma})=\eta_{\infty}+\frac{\eta_{0}-\eta_{\infty}}{\left[1+(\lambda \dot{\gamma})^{a}\right]\left(\frac{1-n}{a}\right)}
\end{aligned}
$$

where $\eta_{0}, \eta_{\infty}, \lambda, a$ and $n$ are their adjustable parameters. It is important to mention that both shear viscosity models were used to fit the measured data keeping the $\eta_{0}$ and $\eta_{\infty}$ parameters fixed, i.e. equal to measured values provided in Table 1. Comparison between experimentally determined 
flow curves and model fits are provided in Figures 3 and Figure 11 in [40] for LCB PP blends and the L-PP, respectively. Root Mean Squared Error (RMSE) defined via Eq. 3 was used to evaluate the fitting error for given polymer sample and the model used.

$R M S E=\sqrt{\frac{1}{\delta} \sum_{i=1}^{\delta}\left[\log \left(\eta_{i}\right)-\log \left(\hat{\eta}_{i}\right)\right]^{2}}$

where $\delta$ is the number of measured points, $\eta_{\mathrm{i}}$ and $\hat{\eta}_{i}$ represent measured and predicted shear viscosity points at given shear rate. Obtained model parameters are summarized in Table 2, 3 .

In the second method, time-temperature superposition principle was applied for the frequency dependent storage $\left(G^{\prime}\right)$ and loss $\left(G^{\prime \prime}\right)$ moduli (measured at 170, 180, 190, 210 and $230{ }^{\circ} \mathrm{C}$ in linear viscoelastic region) to generate master curve at $230{ }^{\circ} \mathrm{C}$, which was consequently fitted by a twomode Maxwell model, Eqs 4 - $5[36,53]$ as shown in Figure 4. Based on these fits, the longest relaxation time, $\lambda_{1}$, for L-PP and LCB-PP blend was found to be $5.36 \mathrm{~ms}$ and $7.95 \mathrm{~ms}$, respectively.

$\mathrm{G}^{\prime}(\omega)=\mathrm{G}_{1} \frac{\omega^{2} \lambda_{1}^{2}}{1+\omega^{2} \lambda_{1}^{2}}+\mathrm{G}_{2} \frac{\omega^{2} \lambda_{2}^{2}}{1+\omega^{2} \lambda_{2}^{2}}$

and

$\mathrm{G}^{\prime \prime}(\omega)=\mathrm{G}_{1} \frac{\omega \lambda_{1}}{1+\omega^{2} \lambda_{1}^{2}}+\mathrm{G}_{2} \frac{\omega \lambda_{2}}{1+\omega^{2} \lambda_{2}^{2}}$

Here $\omega$ is the frequency, $\lambda_{1}$ and $\lambda_{2}$ are the longest and the shortest relaxation times, respectively, and $G_{1}$ and $G_{2}$ are corresponding moduli. 
Extensional viscosities for both investigated samples were determined from the measured entrance pressure drop data using the Gibson model, which is based on the sink flow kinematics with no vortices and it is given by the following equations [54 - 56]:

$$
\begin{aligned}
& \sigma_{\mathrm{E}}=\frac{\overline{\mathrm{P}_{\mathrm{Ent}}}}{[2 /(3 \mathrm{k})]\left[1-\left(\mathrm{R} / \mathrm{R}_{\mathrm{b}}\right)^{3 \mathrm{k}}\right]+\left\{\mathrm{I}(\mathrm{k}, \alpha) /[\sin (\alpha)(1+\cos (\alpha))]^{\mathrm{n}}\right\}} \\
& \overline{\mathrm{P}_{\mathrm{Ent}}}=\mathrm{P}_{\mathrm{Ent}}-2 \tau_{\mathrm{xy}, \mathrm{Cor}}[\sin (\alpha)]^{3 \mathrm{n}}\left[1-\left(\mathrm{R} / \mathrm{R}_{\mathrm{b}}\right)^{3 \mathrm{n}}\right][(3 \mathrm{n}+1) /(4 \mathrm{n})]^{\mathrm{n}} /\left[3 \mathrm{n}(\pi / 2)^{3 \mathrm{n}+1}\right] \\
& \mathrm{I}(\mathrm{k}, \alpha)=\int_{0}^{\alpha}[1+\cos (\beta)]^{\mathrm{k}-1}[\sin (\beta)]^{\mathrm{k}+1} \mathrm{~d} \beta \\
& \dot{\varepsilon}=\frac{1}{4} \dot{\gamma}_{\text {App }} \sin (\alpha)[1+\cos (\alpha)]
\end{aligned}
$$

Here $\overline{\mathrm{P}_{\text {Ent }}}$ represents the entrance pressure drop arising from the uniaxial extensional flow only, $R_{b}$ is the barrel radius, $\alpha$ is the entrance angle, $k$ represents local slope in the $\overline{\mathrm{P}_{\text {Ent }}}$ vs. $\dot{\gamma}_{\text {App }}$ function in $\log -\log$ scale. The term $\mathrm{I}(\mathrm{k}, \alpha)$, which is given by Eq. 8 , needs to be treated numerically.

\section{Melt blown experiment}

Nonwoven samples from L-PP and LCB-PP were produced on the Reifenhäuser Reicofil pilot plant melt blown line (see Figure 5) utilizing the nosepiece die (sharp die) having the following characteristics: total and active width equal to $350 \mathrm{~mm}$ and $250 \mathrm{~mm}$, respectively; orifice diameter: $0.4 \mathrm{~mm}$; number of holes per active part: 470; processing conditions: melt/air temperature: 270 ${ }^{\circ} \mathrm{C}$; collector belt speed: $4 \mathrm{~m} / \mathrm{min}$, die-to-collector distances: 200 and $500 \mathrm{~mm}$. Air volume flow rate was adjusted to be about $390 \mathrm{~m}^{3} / \mathrm{hr}$ for given processing conditions and used polymer to reach 
the same average fiber diameter for all samples, i.e. $10^{3.196 \pm 0.202} \mathrm{~nm}$, keeping the mass flow rate for one orifice the same $(0.0885 \mathrm{~g} / \mathrm{min})$. All performed experiments are summarized in Table 5 . Note that utilized melt blown spinning line is practically identical to an industrial Reicofil melt blown line. The difference is the width of the produced webs and maximum attainable highest line speed, i.e. there is no limitation to mimic production of nonwovens for filter applications, which is typically performed at low line speeds.

\section{Morphological characterization}

For given processing condition and polymer used, two samples with dimensions $10 \mathrm{~mm} \times 10 \mathrm{~mm}$ were cut out from different locations of the produced nonwoven and coated in Polaron SC7640 sputtering device under the following conditions: Argon as protective atmosphere, Palladium as coating material, plasma current $25 \mathrm{~mA}$, voltage $2.1 \mathrm{kV}$, chamber pressure $6 \mathrm{~Pa}$ and all this for 60 seconds. Then, HITACHI Tabletop TM-1000 scanning electron microscope (SEM) was used to visualize nonwoven structure for each sample at three different magnifications $(500 \times, 1000 \times$, $2500 \times$ ) with the following operating conditions: an accelerating voltage $15 \mathrm{kV}$, electron gun: precentered cartridge filament, vacuum pump: turbomolecular pump $30 \mathrm{l} / \mathrm{s} \times 1$ unit and detection system: high-sensitive semiconductor BSE detector. In order to determine basic morphological characteristics of produced nonwovens, the following procedure has been applied by using inhouse developed software (UTBsoft Filtration) at the Faculty of Technology, Tomas Bata University in Zlín. Firstly, skeletonization SEM image processing was applied to determine fiber centerlines and local fiber diameters according to technique proposed in $[57,58]$. Secondly, fiber diameter distribution was fitted by a log-normal function to determine the mean, $d_{a v}$, standard deviation, $\sigma$, and coefficient of variation, $C V$, utilizing the following equations $[8,36-38]$ : 
$f(d)=\frac{1}{\sigma \sqrt{2 \pi}} \exp \left\{-\frac{1}{2 \sigma^{2}}[\log (d)-\mu]^{2}\right\}$

$d_{a v}=10^{\mu \pm \sigma}$

$C V=\sqrt{\exp \left(\sigma^{2}\right)-1}$

It is important to mention that melt blown nonwovens consist of nanofibers as well as microfibers, i.e. combination of SEM images at different magnifications for given sample have to be applied to capture relevant information about thin as well as thick fibers to determine correct, overall fiber diameter distribution. Example of the applied procedure is visualized in Figure 6 for LCB-PP sample $(\mathrm{DCD}=200 \mathrm{~mm})$. As it can be seen, fiber diameter distributions obtained from SEM images at magnification $500 \times, 1000 \times$ and $2500 \times$ contain the most important information about the highest, medium and the lowest fiber diameters, respectively. Thus, the final, overall fiber diameter distribution for given sample and given area is suggested to be given by data overlapping from all three utilized magnifications (see example in Figure 6). It is important to mention that normalized fiber diameter distribution has to be used in order to combine data from different images, which takes into account of both, number of analyzed fiber diameters as well as the analyzed area. In order to handle the sample inhomogeneity (and potentially varied quality of SEM images at different magnifications), one has to utilize more images from different places (especially at the highest magnifications to get correct information about low fiber diameter tail). The UTBsoft program, we have developed, allows to combine an arbitrary number of SEM images with different magnifications to generate one normalized fiber diameter distribution curve. 


\section{RESULTS AND DISCUSSION}

\section{Reptation-mode relaxation time}

Even if the 5 parametric Carreau-Yasuda model has higher fitting capability to describe flow curve for both investigated PP samples than 4 parametric Cross model (see Figure 3 and Table 2, 3), its parameters, namely index of non-Newtonian behavior $n$ and relaxation time $\lambda$ does not seems to have physical meaning when non-zero $\eta_{\infty}$ is considered. In more detail, the Carreau-Yasuda model predicts that, firstly, the relaxation time $\lambda$ is higher for less elastic L-PP in comparison with more elastic LCB-PP blend containing high molecular weight fraction, which is not realistic and secondly, parameter $n$ is the same, practically equal to 0 , for different PPs. Closer analysis has revealed that the model fits the measured data for both samples with the simple $\mathrm{S}$ shape curve with no fully developed power-law regime utilizing $\lambda$ and $a$ fitting parameters only to give the best numerical fit (i.e. the parameter $n$ has no direct physical meaning). In the case of the Cross model, $\lambda$ for more elastic LCB-PP is correctly predicted to be higher $(0.714 \mathrm{~ms})$ in comparison with low elastic L-PP (0.356 ms), which is in good correspondence with the open literature [43, 59]. Amintowlieh et al. has showed that increase in LCBs in PP increases the Cross relaxation time (from $0.6 \mathrm{~s}$ to $1.2 \mathrm{~s}$ ) at practically unchanged polydispersity factor $M_{w} / M_{n}$ (equal to 3.3 for L-PP and 3.7 for branched PP) [59]. Similarly, Münstedt [43] has shown that long chain branching of polyolefines increases the elasticity (characterized by recoverable compliance) even if the molar mass distribution remains the same. Observation that the Cross model gives a meaningful relaxation time while the Carreau-Yasuda model does not despite giving a better numerical fit is further supported by the performed an independent measure of the longest relaxation time obtained by fitting small amplitude oscillatory shear data with a generalized Maxwell model, which was 
found to be higher for LCB-PP $(7.95 \mathrm{~ms})$ in comparison with L-PP $(5.36 \mathrm{~ms})$. The fact that the Cross model gives about one order lower relaxation time in comparison with the longest Maxwell relaxation time can be attributed to its macroscopic nature.

\section{Infinite to zero-shear rate viscosity ratio}

Another way to assess the melt elasticity of melt blown PPs, independently of any fitting model, is determination of $\eta_{\infty} / \eta_{0}$ ratio directly from the measured data summarized in Table 1 . In view of the nonlinear models with objective time derivatives of strain (such as Oldroyd type models, corotational Jeffreys model or Giesekus model), this variable is equal to retardation to relaxation time ratio, $\lambda_{2} / \lambda_{1},[60,61]$ and as shown theoretically by Saengow and Giacomin $[62$, 63], increase in $\eta_{\infty}$ (keeping the $\eta_{0}$ constant) decreases the fluid elasticity. In the uniaxial extensional flow, polymer melt behaves as the Newtonian fluid if the extensional strain rate is below the reciprocal value of the reptation time (where the extensional viscosity is given by Trouton ratio, $\eta_{E, 0}=3 \eta_{0}$ ) or if the strain rates are very high and maximum chain stretch is reached [64]. At these very high deformation rates, it can be reasonable to consider that extensional viscosity is proportional to $\eta_{\infty}$ as $\eta_{E, \infty}=\mathrm{k} \eta_{\infty}$, where $k$ is the material constant characterizing disentangled and fully stretched polymer chains. Thus, $\eta_{\propto} d \eta_{0}$ can be viewed as the parameter, which is directly related to a maximum attainable uniaxial extensional strain hardening $\eta_{E, o d}\left(3 \eta_{0}\right)$ occurring at very high deformation rates where maximum chain stretch occurs. In order to support the validity of this physical interpretation of $\eta_{\propto} d \eta_{0}$ ratio, let us consider the Giesekus model prediction for the normalized uniaxial extensional viscosity $(\alpha \neq 0)[60]$ :

$$
\frac{\eta_{\mathrm{E}}}{3 \eta_{0}}=\frac{\lambda_{2}}{\lambda_{1}}+\left(1-\frac{\lambda_{2}}{\lambda_{1}}\right) \frac{1}{6 \alpha}\left[3+\frac{1}{\lambda_{1} \dot{\varepsilon}}\left\{\left[1-4(1-2 \alpha) \lambda_{1} \dot{\varepsilon}+4 \lambda_{1}^{2} \dot{\varepsilon}^{2}\right]^{1 / 2}-\left[1+2(1-2 \alpha) \lambda_{1} \dot{\varepsilon}+\lambda_{1}^{2} \dot{\varepsilon}^{2}\right]^{1 / 2}\right\}\right]
$$


where $\dot{\varepsilon}$ is the extensional strain rate and $\alpha$ is the nonlinear Giesekus model parameter called as the dimensionless "mobility factor". It is not difficult to show that the following asymptotic formula holds for Eq. 13 (if $\alpha \neq 0$ and $\lambda_{2} / \lambda_{1}$ is substituted by $\eta_{\infty} / \eta_{0}$ in this equation):

$$
\frac{\eta_{E}}{3 \eta_{0}}=\left(1-\frac{2}{3 \alpha}\right) \frac{\eta_{\infty}}{\eta_{0}}+\frac{2}{3 \alpha} \quad(\dot{\varepsilon} \rightarrow \infty)
$$

From Eq.14, it is visible that $\eta_{\infty} / \eta_{0}$ is directly proportional to the normalized uniaxial extensional viscosity at extremely high deformation rates, as expected.

In our recent experimental studies [40,41], it was shown that $\eta_{0}$ and $\eta_{\infty}$ are given for studied polymers as

$$
\begin{aligned}
& \eta_{o}(T)=K_{o}(T) \cdot M_{w}^{n} \\
& \eta_{\infty}(T)=K_{\infty}(T) \cdot M_{w}
\end{aligned}
$$

or

$\eta_{0}(T)=\eta_{0}\left(T_{r}\right) \cdot e^{\frac{E_{0}}{R}\left(\frac{1}{T}-\frac{1}{T_{r}}\right)}$

$\eta_{\infty}(T)=\eta_{\infty}\left(T_{r}\right) \cdot e^{\frac{E_{\infty}}{R}\left(\frac{1}{T}-\frac{l}{T_{r}}\right)}$

where $T$ is the actual temperature, $T_{r}$ is the reference temperature, $M_{w}$ is the weight average molecular weight, $E_{0}$ and $E_{\infty}$ is zero-shear rate and infinite-shear rate flow activation energy, respectively, $R$ is the universal gas constant $(8.314 \mathrm{~J} / \mathrm{K} / \mathrm{mol}), n$ is the power-law exponent and $K$ is the proportionality constant. Combining Eqs. 15 - 16 or Eqs. 17 - 18 the following expressions can be obtained for temperature dependent $\eta_{\infty} / \eta_{0}$ ratio

$\frac{\eta_{\infty}(T)}{\eta_{0}(T)}=\frac{K_{\infty}(T)}{K_{0}(T)} M_{w}^{1-n} \quad$ for $\quad M_{w}>M_{c}$

or 
$\frac{\eta_{\infty}(\mathrm{T})}{\eta_{0}(\mathrm{~T})}=\frac{\eta_{\infty}\left(\mathrm{T}_{\mathrm{r}}\right)}{\eta_{0}\left(\mathrm{~T}_{\mathrm{r}}\right)} \mathrm{e}^{\frac{-\left(\mathrm{E}_{0}-\mathrm{E}_{\infty}\right)}{\mathrm{R}}\left(\frac{1}{\mathrm{~T}}-\frac{1}{\mathrm{~T}_{\mathrm{r}}}\right)}$

where $M_{c}$ is a critical molecular weight, which is approximately $2-3$ times the molecular weight $6900 \mathrm{~g} / \mathrm{mol}$ between chain entanglements for isotactic PP $[65,66]$. In order to clarify the role of the molecular weight and temperature on the $\eta_{\infty} / \eta_{0}$ ratio, both equations are visualized in Figure 7 for studied linear and branched PPs utilizing experimentally determined parameters summarized in Tables 1,6 . As it can be seen, $\eta_{\infty} / \eta_{0}$ decreases with increased molecular weight and increases with increased temperature for both samples. The most importantly, LCB-PP sample shows lower value of $\eta_{\infty} / \eta_{0}$ (due to higher power-law exponent $n$ ) and stronger temperature dependence (due to higher difference between $E_{0}$ and $E_{\infty}$ ) in comparison with L-PP at the given $M_{w}$ and temperature ranges.

\section{Extensional rheology}

Deformation rate dependent uniaxial extensional viscosity data for both tested PPs are provided in Figure 8 . As it can be seen, extensional viscosity firstly decreases with increased extensional strain rate to its minimum value at $200000-400000$ 1/s, (where the strain rates can be considered to be comparable with the inverse of the Rouse time) and then increases (due to starting occurrence of the chain stretch) to plateau value, $\eta_{E, \infty}$ (corresponding to the maximum chain stretch) at about $2 \cdot 10^{6} 1 / \mathrm{s}$. At low deformation rates, extensional viscosity is higher for LCB-PP in comparison with L-PP, but the trend is switched at very high deformation rates and $\eta_{E, \infty}$ (and also $\eta_{E, \infty} / 3 \eta_{0}$ ) becomes lower for LCB-PP in comparison with L-PP. Interestingly, reduction in $\eta_{E, \infty} / 3 \eta_{0}$ due to LCB is in good qualitative agreement with the prediction of Eq. 19 for $\eta_{\infty} / \eta_{0}$ visualized in Figure 
7, which underlines importance and usefulness of this material parameter obtained from shear viscosity data.

Note that the experimental data provided in Figure 8 are based on three independent entrance pressure drop measurements at different volume flow rates. It should also be mentioned that the used Gibson model to estimate extensional rheology is based on sink flow kinematics to describe the entrance pressure drop in constrained convergence considering that the dominant source of the entrance pressure drop is extensional flow, which does not depend strongly on the velocity profile across the die. Thus, the Gibson model is not able to describe or predict the formation of recirculation zones [55]. The maximum attainable extensional strain during abrupt contraction flow can be calculated as

$\varepsilon_{\text {max }}=2 \ln \left(\frac{\mathrm{D}_{\mathrm{b}}}{\mathrm{D}_{\mathrm{d}}}\right)$

where $D_{b}$ and $D_{d}$ is the barrel $(15 \mathrm{~mm})$ and the orifice die $(0.5 \mathrm{~mm})$ diameter, respectively [67]. According to Eq. (21), $\varepsilon_{\max }$ is 6.8 in this case.

\section{Understanding of melt blown process dynamics}

SEM images, fiber diameter distributions and log-normal function fits for produced LCBPP and L-PP nonwovens at two different DCD distances are provided in Figures $9-12$, whereas obtained $C V$ values are plotted in Figures $13-14$ as the function of the longest Maxwell relaxation time and $\eta_{\infty} / \eta_{0}$ (both shifted to the processing temperature $270{ }^{\circ} \mathrm{C}$ via Eq. 20 ; see Table 4). It is clearly visible that, $C V$ decreases with decreased $\eta_{\infty} / \eta_{0}$ (i.e with $\eta_{E, \infty}$ ) and with increased elasticity, 
$\lambda_{1}$, for both DCD distances as well as decrease in DCD distance reduces $C V$. As it can be seen in Figure 14, obtained trend between $C V$ and $\lambda_{1}$ is in good agreement with the experimental work of Tan et al. [36] who used different PS with similar $\eta_{0}$ but different elasticity (also characterized by the longest relaxation time, $\lambda_{1}$, determined via fitting of frequency dependent loss and storage moduli master curve by a two-mode Maxwell model and shifted to melt blowing temperature). Differences between $C V$ for PP and PS (even if the fiber diameter is comparable in both cases) can be attributed to different values of Rouse time (which is much higher for PS in comparison to with $\mathrm{PP}$ ) as well as due to different extensional rheology. The fact, that $C V$ varies with DCD even if $\lambda_{1}$ or $\eta_{\infty} / \eta_{0}$ is unchanged suggests that knowledge of deformation rate dependent rheological parameters rather than their limiting values should be preferred to fully understand melt blown process dynamics. Note that $C V$ values reported in this work are comparable with $C V$ values (50 $\%$ ) for nonwovens with average fiber diameter $6 \mu \mathrm{m}$ (made from PPs with $\mathrm{M}_{\mathrm{w}}=175 \mathrm{~kg} / \mathrm{mol}$ [6]) but much lower than $C V$ values ( $88 \%$ ) for PP nonwovens with and $\mathrm{M}_{\mathrm{w}}=42 \mathrm{~kg} / \mathrm{mol}$ and average fiber diameter $0.774 \mu \mathrm{m}[7]$.

As it can be seen in Figure 15, there is combination of extensional and shear flows in the post die area during the melt blown process. Thus the final diameter distribution is given by the shear viscosity $[7,36]$, the shear elasticity [36] and the uniaxial extensional viscosity of the polymer melt. As shown above, $\eta_{\propto} / \eta_{0}$ parameter characterizes normalized infinite uniaxial extensional viscosity $\eta_{E, d} d\left(3 \eta_{0}\right)$ occurring at very high extensional strain rates, i.e. at about $1.5-$ $2 \cdot 10^{6} 1 / \mathrm{s}$ for tested PP melts as visible in Figure 8 . Due to the fact that fiber attenuation in melt blowing process is associated with extensional strain rates in order of millions reciprocal seconds [36], the $\eta_{\propto} \eta_{0}$ can be considered as an additional useful parameter to understand behaviour of polymer melts in such flow conditions. 
In more detail, the extensional strain rate is the highest at the die exit (region I in Figure 15 where the air speed is the highest) and then it starts to decrease with the drawing distance due to decreased air speed (region II in Figure 15). Due to the fact that the LCB-PP sample has lower $\eta_{\propto d} \eta_{0}$ (i.e. higher stretching ability at extremely high deformation rates) and lower infinite shear viscosity $\eta_{\infty}$ than L-PP sample, it can reduce the fiber diameter in region I more effectively than the L-PP sample. In region II, i.e. at medium and low deformation rates, the elongational viscosity of LCB-PP sample is higher in comparison with L-PP and thus, L-PP can be stretched more intensively than LCB-PP sample. However, the melt stretching can be considered to be more unstable in region II due to occurrence of high melt/air inertia driven bending instability called whipping $[8,14-24]$. Thus, for the specific processing conditions leading to the same fiber diameter for LCB-PP and L-PP samples (like in the performed experiments), $C V$ is lower for LCBPP in comparison with L-PP and the stabilizing effect is more pronounced for smaller DCDs. Additionally, from Eq.19 visualized graphically in Figure 7, it can be seen that increase in zero and infinite flow activation energies difference, $E_{0}-E_{\infty}$, (via adding of high molecular weight LCB-PP into low molecular weight L-PP in this work) causes stronger decrease of $\eta_{\circ d} \eta_{0}$ (i.e. $\left.\eta_{E, d}\left(3 \eta_{0}\right)\right)$ with decreased melt temperature in comparison with L-PP. From this, it can be deduced that LCB-PP melt becomes more stretchable at extremely high deformation rates than L-PP melt even if the temperature is decreased due to intensive melt cooling at the die exit (region I). This can be considered as additional stabilizing factor reducing $C V$ of fiber diameters.

It is important to mention that presence of the "nonuniform" fibers, captured here via $C V$, is very important to nonwoven performance because it leads to broader pore size distribution and generation of more anisotropic structures, which decreases mechanical properties and filtration characteristics of nonwovens [68, 69]. 


\section{CONCLUSION}

In this work, L-PP and LCB-PP blend, both having comparable $\mathrm{M}_{\mathrm{w}}(76-78 \mathrm{~kg} / \mathrm{mol})$, zero-shear viscosity $\left(22.8-24.51 \mathrm{~Pa} \cdot \mathrm{s}\right.$ at $\left.230{ }^{\circ} \mathrm{C}\right)$ and polydispersity $\mathrm{M}_{\mathrm{w}} / \mathrm{M}_{\mathrm{n}}(4.41-4.50)$ were used to produce nonwovens via melt blown technology at constant temperature $\left(270^{\circ} \mathrm{C}\right)$ and two different die-to-collector distances $(200 \mathrm{~mm}$ and $500 \mathrm{~mm}$ ) in order to understand role of long chain branching on the fiber diameter distribution. Melt elasticity was evaluated via macroscopic relaxation time determined by shear viscosity data fitting by Cross and Carreau-Yasuda models and the longest relaxation time obtained by fitting small amplitude oscillatory shear data with a generalized Maxwell model. Extensional rheology was assessed by the strain rate dependent uniaxial extensional viscosity (estimated from the entrance pressure drop using the Gibson method) as well as through $\eta_{\infty} / \eta_{0}$ ratio (obtained directly from the measured experimental data), which is proportional to the maximum normalized extensional viscosity at very high extensional strain rates, $\eta_{E, \mathrm{~d}}\left(3 \eta_{0}\right)$. Basic morphological characteristics of produced nonwoven samples have been determined using digital image analysis of SEM images considering three different magnifications to capture nanofibers as well as microfibers.

It has been found that firstly, Carreau-Yasuda relaxation time is unrealistically higher for less elastic L-PP in comparison with more elastic LCB-PP blend and power-law index remains artificially the same, practically equal to 0 , for both samples. In the case of the Cross model, relaxation time for more elastic LCB-PP was correctly predicted to be higher in comparison with low elastic L-PP, which is in good correspondence with the open literature as well as with the longest Maxwell relaxation time obtained from frequency dependent loss and storage moduli measurements. Secondly, extensional viscosity for both samples decreases with increased 
extensional strain rate to its minimum value at $200000-4000001 / \mathrm{s}$, and then increases to plateau value, $\eta_{E, \infty}$ at about $2 \cdot 10^{6} 1 / \mathrm{s}$. Thirdly, extensional viscosity (and also $\eta_{E, \infty} / 3 \eta_{0}$, which is proportional to $\left.\eta_{\infty} / \eta_{0}\right)$, is lower for LCB-PP in comparison with L-PP at very high deformation rates, but the trend is switched at low deformation rates and extensional viscosity becomes higher for LCB-PP in comparison with L-PP. Fourthly, fiber diameter distribution (coefficient of variation, $C V$ ) for the nonwovens produced via melt blown technology is lower for LCB-PP blend in comparison with L-PP sample fifthly, decrease in die-to-collector distance reduces $C V$ and finally, simple relationship between $\eta_{\infty} / \eta_{0}$ (which is proportional to $\eta_{E, \infty} / 3 \eta_{0}$ ), temperature and basic molecular characteristics of both samples was formulated.

It has been suggested that high stability of LCB-PP blend can be explained by its higher stretchability at very high deformation rates (occurring at the die exit where an intensive fiber attenuation takes the place) and its lower stretchability at medium and low deformation rates, at which melt/air inertia driven bending instability called whipping occurs.

Obtained results suggests, that utilization of low molecular weight and branched polymers can stabilize production of polymeric nanofibers and microfibers through melt blown technology considerably. It is believed, that above described findings provides new rheological insight to designing polymers for the melt blown process and represents useful experimental data for validation or development of advanced molecular based constitutive equations considering the effect of chain stretch on the extensional viscosity rise (until maximum stretch is achieved) at the strain rates, which are higher than the reciprocal value of the Rouse time. 


\section{ACKNOWLEDGMENTS}

The authors wish to acknowledge Grant Agency of the Czech Republic (Grant registration No. 1605886S) for the financial support. The authors also wish to acknowledge Joachim Fiebig from Borealis Polyolefine (Linz, Austria) for donation of the polypropylene melt blown samples, help with the GPC measurements and to allowing us to perform all melt blown experiments as well as scanning electron microscopy on Borealis Polyolefine laboratory equipment. 


\section{REFERENCES}

[1] LAWRENCE, K. D., R. T. LUCAS, J. A. YOUNG, An improved device for the formation of superfine, thermoplastic fibers. U. S. NAVAL RESEARCH

LABORATORY, WASHINGTON D. C. . 1959.

[2] HASSAN, M. A., B. Y. YEOM, A. WILKIE, B. POURDEYHIMI, S. A. KHAN, Fabrication of nanofiber meltblown membranes, and their filtration properties, Journal of Membrane Science. 2013, vol. 427, p. 336 - 344.

[3] HAYES, B. D., An experimental and analytical investigation on the production of microfibers using a single-hole melt blowing process, Ph.D Thesis. The University of Tennessee, Knoxville, USA, 1991.

[4] MALKAN, S. R., Process-structure-property relationships in different molecular weight polypropylene melt-blown webs, Ph.D Thesis. The University of Tennessee, Knoxville, USA, 1990.

[5] MALKAN, S. R., L. C. WADSWORTH, Polymer-laid systems, In A. TURBAK (Ed.), Nonwovens: Theory, process, performance, and testing. 1993, Atlanta: TAPPI Press, p. $171-192$.

[6] SHAMBAUGH, R. L., A Macroscopic View of the Melt-Blowing Process for Producing Microfibers, Industrial and Engineering Chemistry Research. 1988, vol. 27, p. 2363 2372.

[7] NAYAK, R., I. L. KYRATZIS, Y. B. TRUONG, R. PADHYE, L. ARNOLD, G. PEETERS, M. O'SHEA, L. NICHOLS, Fabrication and characterization of polypropylene nanofibers by meltblowing process using different fluids, Journal of Materials Science. 2013, vol. 48, no. 1, p. 273 - 281. 
[8] ELLISON, C. J., A. PHATAK, D. W. GILES, C. W. MACOSKO and F. S. BATES, Melt blown nanofibers: fiber diameter distributions and onset of fiber breakup, Polymer. 2007, vol. 48 , no. 11 , p. $3306-3316$.

[9] DUTTON, K. C., Overview and analysis of the meltblown process and parameters, Journal of Textile and Apparel, Technology and Management. 2008, vol. 6, no. 1.

[10] DAS, D., A. K. PRADHAN, R. ChATTOPADHYAY, S. N. SINGH, Composite nonwovens, Textile Progress. 2012, vol. 44, no. 1, p. 1 - 84.

[11] ECKSTEIN, A., C. FRIEDRICH, A. LOBBRECHT, R. SPITZ, Comparison of the viscoelasticproperties of syndio- and isotactic polypropylenes, Acta Polymerica. 1997, vol. 48 , p. $41-46$.

[12] GAHLEITNER M., Melt rheology of polyolefins, Progress in Polymer Science. 2001, vol. 26 , no. 6 , p. $895-944$.

[13] DRABEK, J., M. ZATLOUKAL, Evaluation of thermally induced degradation of branched polypropylene by using rheology and different constitutive equations, Polymers. 2016, vol. 8, no. 9, Art. n. 317.

[14] XIE, S., Y. ZHENG and Y. ZENG, Influence of die geometry on fiber motion and fiber attenuation in the melt-blowing process, Industrial and Engineering Chemistry Research. 2014, vol. 53, no. 32, p. $12866-12871$.

[15] CHHABRA, R. and R. L. SHAMBAUGH, Experimental measurements of fiber threadline vibrations in the melt-blowing process, Industrial and Engineering Chemistry Research. 1996, vol. 35, no. 11, p. $4366-4374$.

[16] HAN, W. and X. WANG, Modeling melt blowing fiber with different polymer constitutive equations, Fibers and Polymers. 2016, vol. 17, no. 1, p. $74-79$. 
[17] ZENG, Y. C., Y. F. SUN and X. H. WANG, Numerical approach to modeling fiber motion during melt blowing, Journal of Applied Polymer Science. 2011, vol. 119, no. 4, p. $2112-2123$.

BEARD, J. H., R. L. SHAMBAUGH, B. R. SHAMBAUGH and D. W. SCHMIDTKE, On-line measurement of fiber-motion during melt blowing, Industrial and Engineering Chemistry Research. 2007, vol. 46, no. 22, p. $7340-7352$.

[19] XIE, S. and Y. ZENG, Online measurement of fiber whipping in the melt-blowing process, Industrial and Engineering Chemistry Research. 2013, vol. 52, no. 5, p. 2116 2122.

[20] SUN, Y., Y. ZENG and X. WANG, Three-dimensional model of whipping motion in the processing of microfibers, Industrial and Engineering Chemistry Research. 2011, vol. 50, no. 2 , p. $1099-1109$.

[21] XIE, S. and Y. ZENG, Turbulent air flow field and fiber whipping motion in the melt blowing process: Experimental study, Industrial and Engineering Chemistry Research. 2012, vol. 51 , no. 14 , p. $5346-5352$.

[22] RAO, R. S. and R. L. SHAMBAUGH, Vibration and stability in the melt blowing process, Industrial and Engineering Chemistry Research. 1993, vol. 32, no. 12, p. 3100 3111.

[23] CHUNG, C. and S. KUMAR, Onset of whipping in the melt blowing process, Journal of Non-Newtonian Fluid Mechanics. 2013, vol. 192, p. 37 - 47.

[24] XIE, S., W. HAN, G. JIANG, C. CHEN, Turbulent air flow field in slot-die melt blowing for manufacturing microfibrous nonwoven materials, Journal of Materials Science. 2018, vol. 53 , no. 9 , p. $6991-7003$. 
[25] HAN, W., G. S. BHAT and X. WANG, Investigation of nanofiber breakup in the meltblowing process, Industrial and Engineering Chemistry Research. 2016, vol. 55, no. 11, p. $3150-3156$.

[26] BRESEE, R. R., Fiber motion near the collector during melt blowing: part 2 - fly formation, International Nonwovens Journal. 2002, vol. 11, no. 3, p. 21 - 27.

[27] VARGAS, E., Meltblown technology Today: an overview of raw materials, processes, products, markets, and emerging end uses. San Francisco, USA: California: Miller Freeman, 1989, 1 - 316, ISBN: 9780879301767

[28] TAN, D. H., P. K. HERMAN, A. JANAKIRAMAN, F. S. BATES, S. KUMAR, C. W. MACOSKO, Influence of Laval nozzles on the air flow field in melt blowing apparatus, Chemical Engineering Science. 2012, vol. 80, p. 342 - 348.

[29] MOORE, E. M., D. V., PAPAVASSILIOU, R. L. SHAMBAUGH, Air velocity, air temperature, fiber vibration and fiber diameter measurements on a practical melt blowing die, International Nonwovens Journal. 2004, vol. 13, no. 3, p. 43 - 53.

[30] MUSIL, J. and M. ZATLOUKAL, Historical review of die drool phenomenon in plastic extrusion, Polymer Reviews. 2014, vol. 54, no. 1, p. $139-184$.

[31] MUSIL, J. and M. ZATLOUKAL, Historical review of secondary entry flows in polymer melt extrusion, Polymer Reviews. 2018, DOI: 10.1080/15583724.2018.1481428.

[32] GAHAN, R. and G. C. ZGURIS, A review of the melt blown process, Proceeding of the Annual Battery Conference on Applications and Advances. 2000, vol. 2000, p. 145 - 149.

[33] BHAT, G. S. and S. R. MALKAN, Polymer-laid web formation. In: Handbook of nonwovens, RUSSELL S. J., Woodhead publishing in textiles. Cambridge, England: CRC Press, 2007, 143 - 195. ISBN 9781855736030 
[34] KO, W. C. and R.R. BRESEE, FT-IR microspectroscopic study of shot formation in meltblown webs, Applied Spectroscopy. 2003, vol. 57, no. 6, p. $636-641$.

BRESEE, R. R., Influence of processing conditions on melt blown web structure. Part III - water quench, International Nonwovens Journal. 2005, vol. 14, no. 4, p. 27 - 35.

[36] TAN, D. H., C. ZHOU, C. J. ELLISON, S. KUMAR, C. W. MACOSKO and F. S. BATES, Meltblown fibers: influence of viscosity and elasticity on diameter distribution, Journal of Non-Newtonian Fluid Mechanics. 2010, vol. 165, no. 15 - 16, p. 892 - 900.

[37] SOLTANI, I., C. W. MACOSKO, Influence of rheology and surface properties on morphology of nanofibers derived from islands-in-the-sea meltblown nonwovens, Polymer, 2018, vol. 145, p. $21-30$.

[38] LIMPERT, E., W. A. STAHEL, M. ABBT, Log-normal distributions across the sciences: keys and clues, BioScience. 2001, vol. 51, no. 5, p. $341-352$.

[39] ZHOU, C., D. H. TAN, A. P. JANAKIRAMAN, S. KUMAR, Modeling the melt blowing of viscoelastic materials, Chemical Engineering Science. 2011, vol. 66, no. 18, p. 4172 4183.

[40] DRABEK, J., M. ZATLOUKAL, M. MARTYN, Effect of molecular weight on secondary Newtonian plateau at high shear rates for linear isotactic melt blown polypropylenes, Journal of Non-Newtonian Fluid Mechanics. 2018, vol. 251, p. 107 118.

[41] DRABEK, J., M. ZATLOUKAL, M. MARTYN, Effect of molecular weight, branching and temperature on dynamics of polypropylene melts at very high shear rates, Polymer. 2018, vol. 144, p. $179-183$. 
[42] AUHL, D., F. J. STADLER and H. MÜNSTEDT, Rheological properties of electron beam-irradiated polypropylenes with different molar masses, Rheologica Acta. 2012, vol. 51 , no. $11-12$, p. $979-989$.

[43] MÜNSTEDT, H. and D. AUHL, Rheological measuring techniques and their relevance for the molecular characterization of polymers, Journal of Non-Newtonian Fluid Mechanics. 2005, vol. 128, no. 1, p. $62-69$.

[44] AUHL, D., F. J. STADLER and H. MÜNSTEDT, Comparison of molecular structure and rheological properties of electron-beam and gamma-irradiated polypropylene,

Macromolecules. 2012, vol. 45, no. 4, p. 2057 - 2065.

[45] MÜNSTEDT, H., Rheological properties and molecular structure of polymer melts, Soft Matter. 2011, vol. 7, no. 6, p. $2273-2283$.

[46] AHIRWAL, D., S. FILIPE, I. NEUHAUS, M. BUSCH, G. SCHLATTER and M. WILHELM, Large amplitude oscillatory shear and uniaxial extensional rheology of blends from linear and long-chain branched polyethylene and polypropylene, Journal of Rheology. 2014, vol. 58, no. 3, p. $635-658$.

[47] GABRIEL, C. and H. MÜNSTEDT, Strain hardening of various polyolefins in uniaxial elongational flow, Journal of Rheology. 2003, vol. 47, no. 3, p. $619-630$.

[48] PIVOKONSKY, R., M. ZATLOUKAL, P. FILIP, C. TZOGANAKIS, Rheological characterization and modeling of linear and branched metallocene polypropylenes prepared by reactive processing, Journal of Non-Newtonian Fluid Mechanics. 2009, vol. 156, n. $1-2$, p. $1-6$. 
[49] MAROUFKHANI, M., N. GOLSHAN EBRAHIMI, Melt rheology of linear and longchain branched polypropylene blends, Iranian Polymer Journal. 2015, vol. 24, no. 9, p. $715-724$.

[50] WAGNER, M. H, S. KHEIRANDISH, J. STANGE, H. MÜNSTEDT, Modeling elongational viscosity of blends of linear and long-chain branched polypropylenes, Rheologica Acta. 2006, vol. 46, no. 2, p. $211-221$.

[51] TABATABAEI, S. H., P. J. CARREAU, A. AJJI, Rheological and thermal properties of blends of a long-chain branched polypropylene and different linear polypropylenes, Chemical Engineering Science. 2009, vol. 64, no. 22, p. 4719 - 4731.

[52] STANGE, J., C. UHL, H. MÜNSTEDT, Rheological behavior of blends from a linear and a long-chain branched polypropylene, Journal of Rheology. 2005, vol. 49, no. 5, p. $1059-1079$.

[53] MACOSKO, C. W., Rheology: Principles, measurements, and applications, New York, USA: Wiley VCH Publishers. Inc., 1994, p. 568, ISBN: 9780471185758.

[54] GIBSON, A. G., Die entry flow of reinforced polymers, Composites. 1989, vol. 20, no. 1, p. $57-64$.

[55] ZATLOUKAL, M., J. VLCEK, C. TZOGANAKIS, P. SAHA, Improvement in techniques for the determination of extensional rheological data from entrance flows: computational and experimental analysis, Journal of Non-Newtonian Fluid Mechanics. 2002, vol. 107, n. $1-3$, p. $13-37$.

[56] ZATLOUKAL, M., J. MUSIL, Analysis of entrance pressure drop techniques for extensional viscosity determination, Polymer Testing. 2009, vol. 28, no. 8, p. $843-853$. 
[57] SAMBAER, W., M. ZATLOUKAL, D. KIMMER, 3D modeling of filtration process via polyurethane nanofiber based nonwoven filters prepared by electrospinning process, Chemical Engineering Science. 2011, vol. 66, no. 4, p. 613 - 623.

[58] SAMBAER, W., M. ZATLOUKAL, D. KIMMER, 3D air filtration modeling for nanofiber based filters in the ultrafine particle size range, Chemical Engineering Science. 2012, vol. 82, p. $299-311$.

[59] AMINTOWLIEH, Y., C. TZOGANAKIS, A. PENLIDIS, Continous modification of polypropylene via photoinitiation, Polymer Engineering and Science. 2015, vol. 55, no. 10 , p. $2423-2432$.

[60] BIRD, R., B. ARMSTRONG, O. HASSAGER, Dynamics of polymer liquids. New York, John Wiley, 1987, p. 672, ISBN: 9780471802457.

[61] LARSON, R. G., Constitutive equations for polymer melts and solutions, Boston, Butterworths, 1988, p. 380, ISBN: 9781483130446.

[62] SAEGOW, C., A. J. GIACOMIN, Exact solutions for oscillatory shear sweep behaviors of complex fluids from the Oldroyd 8-constant framework, Physics of Fluids. 2018, vol. 30 , no. 3 , art. no. 030703 .

[63] SAEGOW, C., A. J. GIACOMIN, Strain sweeps from Oldroyd 8-constant framework, AIP Conference Proceedings. 2017, vol. 1843, art. no. 040003.

[64] DELAY, J. M., D. J. READ, R. G. LARSON, Structure and rheology of molten polymers: from structure to flow behavior and back again, $2^{\text {nd }}$ edition, Cincinnati, Hanser, 2018, p. 610, ISBN: 9781569906118.

[65] ECKSTEIN, A., J. SUHM, C. FRIEDRICH, R.-D. MAIER, J. SASSMANNSHAUSEN, M. BOCHMANN, R. MÜLHAUPT, Determination of plateau moduli and entanglement 
molecular weights of isotactic, syndiotactic, and atactic polypropylenes synthesized with metallocene catalysts, Macromolecules. 1998, vol. 31, p. 1335 - 1340.

[66] MÜNSTEDT, H., F. R. SCHWARZL, Deformation and flow of polymeric materials, Heidelberg, Springer, 2014, p. 558, ISBN: 9783662507773.

[67] PADMANABHAN, M., C.W. MACOSKO, Extensional viscosity from entrance pressure drop measurements, Rheologica Acta. 1997, vol. 36, no. 2, p. 144-151.

[68] SAMBAER, W., M. ZATLOUKAL, D. KIMMER, The use of novel digital image analysis technique and rheological tools to characterize nanofiber nonwovens, Polymer Testing. 2010, vol. 29, no. 1, p. $82-94$.

[69] CAI, R. R., H. LU, L. Z. ZHANG, Evaluation the effect of fiber alignment on particle collection performance of mechanical/electret filters based on Voronoi tessellations, Chemical Engineering Science. 2019, vol. 197, p. 109 - 119.

[70] WANG, X., Q. KE, Experimental investigation of adhesive meltblown web production using accessory air, Polymer Engineering and Science. 2006, vol. 46, no. 1, p. 1 - 7. 
TABLE 1. Basic characteristics of utilized PP samples summarized from our prevous work [40, 41]

\begin{tabular}{|c|c|c|c|c|c|c|c|c|c|}
\hline $\begin{array}{l}\text { Sample } \\
\text { Name }\end{array}$ & $\begin{array}{c}M_{n} \\
(\mathrm{~g} / \mathrm{mol})\end{array}$ & $\begin{array}{c}M_{w} \\
(g / m o l)\end{array}$ & $\begin{array}{c}M_{z} \\
(\mathrm{~g} / \mathrm{mol})\end{array}$ & $\begin{array}{c}M_{z+1} \\
(\mathrm{~g} / \mathrm{mol})\end{array}$ & $\begin{array}{c}M_{w} / M_{n} \\
(-)\end{array}$ & $\begin{aligned} & \eta_{0}\left(230{ }^{\circ} \mathrm{C}\right) \\
&(\mathrm{Pa} \cdot \mathrm{s})\end{aligned}$ & $\begin{array}{c}\eta_{\infty}\left(230{ }^{\circ} \mathrm{C}\right) \\
(\mathrm{Pa} \cdot \mathrm{s})\end{array}$ & $\begin{array}{c}E_{0} \\
(k J / m o l)\end{array}$ & $\begin{array}{c}E_{\infty} \\
(k J / m o l)\end{array}$ \\
\hline $\begin{array}{l}\text { HL512FB } \\
\text { (L-PP, 56k) }\end{array}$ & 14250 & 56250 & 114500 & 187500 & 3.95 & $7.79 \pm 0.312$ & $0.165 \pm 0.0005$ & \multirow{2}{*}{56.590} & \multirow{2}{*}{25.204} \\
\hline $\begin{array}{l}\text { HL504FB } \\
\text { (L-PP, 76k) }\end{array}$ & 17200 & 75850 & 165500 & 278000 & 4.41 & $22.80 \pm 1.149$ & $0.229 \pm 0.0025$ & & \\
\hline $\begin{array}{c}30 \mathrm{wt} \% \\
\text { LCB-PP blend, } \\
78 \mathrm{k}\end{array}$ & 17350 & 78150 & 191000 & 373500 & 4.50 & $24.51 \pm 0.973$ & $0.216 \pm 0.0024$ & 59.539 & 23.367 \\
\hline $\begin{array}{c}\text { Daploy } \\
\text { (LCB-PP, 247k) }\end{array}$ & 36950 & 246500 & 815000 & 1705000 & 6.67 & $2379.33 \pm 8.783$ & - & 65.698 & - \\
\hline
\end{tabular}

TABLE 2. Cross model fitting parameters for each material at $\mathrm{T}=230^{\circ} \mathrm{C}$

\begin{tabular}{|cccccc|}
\hline $\begin{array}{c}\text { Sample } \\
\text { Name }\end{array}$ & $\begin{array}{c}\boldsymbol{\eta}_{\boldsymbol{0}} \\
\mathbf{( P a} \cdot \mathbf{s})\end{array}$ & $\begin{array}{c}\boldsymbol{\lambda} \\
(\mathbf{m s})\end{array}$ & $\begin{array}{c}\boldsymbol{a} \\
(-)\end{array}$ & $\begin{array}{c}\boldsymbol{\eta}_{\infty} \\
(\mathbf{P a} \cdot \mathbf{s})\end{array}$ & RMSE \\
\hline HL504FB (L-PP), 76k & $22.80^{*}$ & $0.356^{*}$ & $0.91662^{*}$ & $0.229^{*}$ & $0.047119^{*}$ \\
\hline 30wt\% LCB-PP blend, 78k & 24.51 & 0.714 & 0.84243 & 0.216 & 0.140986 \\
\hline
\end{tabular}

*Data are taken from [40]

TABLE 3. Carreau-Yasuda model fitting parameters for each material at $\mathrm{T}=230{ }^{\circ} \mathrm{C}$

\begin{tabular}{|ccccccc|}
\hline $\begin{array}{c}\text { Sample } \\
\text { Name }\end{array}$ & $\begin{array}{c}\boldsymbol{\eta}_{\boldsymbol{0}} \\
(\mathbf{P a} \cdot \mathbf{s})\end{array}$ & $\begin{array}{c}\lambda \\
(\mathbf{m s})\end{array}$ & $\begin{array}{c}\boldsymbol{a} \\
(-)\end{array}$ & $\begin{array}{c}\boldsymbol{N} \\
(-)\end{array}$ & $\begin{array}{c}\boldsymbol{\eta}_{\boldsymbol{\infty}} \\
(\mathbf{P a} \cdot \mathbf{s})\end{array}$ & RMSE \\
\hline HL504FB (L-PP), 76k & $22.80^{*}$ & $0.222^{*}$ & $0.71466^{*}$ & $1 \times 10^{-12^{*}}$ & $0.229^{*}$ & $0.040775^{*}$ \\
\hline 30wt\% LCB-PP blend, 78k & 24.51 & 0.175 & 0.50823 & $1 \times 10^{-12}$ & 0.216 & 0.099320 \\
\hline
\end{tabular}

*Data are taken from [40]

TABLE 4. Basic rheological characteristics shifted to the melt blown processing temperature via Arrhenius shift factor

\begin{tabular}{|ccccccc|}
\hline $\begin{array}{c}\text { Sample } \\
\text { Name }\end{array}$ & $\begin{array}{c}\boldsymbol{T} \\
\left({ }^{\mathbf{o}} \mathbf{C}\right)\end{array}$ & $\begin{array}{c}\boldsymbol{\eta}_{\mathbf{o}}(T) \\
(\mathbf{P a} \cdot \mathbf{s})\end{array}$ & $\begin{array}{c}\lambda_{\text {cross }}(T) \\
(\mathbf{m s})\end{array}$ & $\begin{array}{c}\lambda_{\text {carreau-Yasuda }}(T) \\
(\mathbf{m s})\end{array}$ & $\begin{array}{c}\lambda_{1, \text { Maxwell }}(T) \\
(\mathbf{m s})\end{array}$ & $\begin{array}{c}\eta_{\text {oo }}(T) / \eta_{0}(T) \\
(-)\end{array}$ \\
\hline HL504FB (L-PP), 76k & 270 & 8.42 & 0.131 & 0.082 & 1.978 & $174.5 \cdot 10^{-4}$ \\
\hline 30wt\% LCB-PP blend, 78k & 270 & 8.59 & 0.250 & 0.061 & 2.780 & $166.6 \cdot 10^{-4}$ \\
\hline
\end{tabular}


TABLE 5. Summarization of melt blown experimental data, $\mathrm{T}=270^{\circ} \mathrm{C}$, Speed belt $=4 \mathrm{~m} / \mathrm{min}$

\begin{tabular}{|c|c|c|c|c|}
\hline \multirow{2}{*}{ Sample No. } & \multirow{2}{*}{$\begin{array}{c}\text { Newtonian } \\
\text { viscosity } \\
{[\mathrm{Pa} \cdot \mathrm{s}]}\end{array}$} & $\begin{array}{c}\text { Die to } \\
\text { collector } \\
\text { distance } \\
{[\mathbf{m m}]}\end{array}$ & $\begin{array}{c}\text { Coeficient } \\
\text { of variation } \\
{[\%]}\end{array}$ & $\begin{array}{c}\text { Standard } \\
\text { deviation } \\
{[\%]}\end{array}$ \\
\hline HL504FB (L-PP), 76k & \multirow{2}{*}{8.42} & 200 & 54.46 & 0.080 \\
\cline { 3 - 5 } & & 500 & 54.84 & 1.345 \\
\hline \multirow{2}{*}{$30 \mathrm{wt} \%$ LCB-PP blend, 78k } & \multirow{2}{*}{8.59} & 200 & 40.12 & 1.940 \\
\cline { 3 - 5 } & & 500 & 47.27 & 2.515 \\
\hline
\end{tabular}

TABLE 6. Summarization of material constants appearing in Eqs. 15 - 16 and 19 (experimentaly determined in [40, 41])

\begin{tabular}{|c|c|c|c|c|c|}
\hline \multirow{2}{*}{ Material } & \multicolumn{2}{|c|}{$\boldsymbol{K}_{\boldsymbol{0}}\left[\mathbf{P a} \cdot \mathbf{s} \cdot(\mathbf{m o l} / \mathbf{k g})^{\mathbf{1 / n}}\right]$} & \multicolumn{2}{|c|}{$\boldsymbol{K}_{\boldsymbol{o}}\left[\mathbf{P a} \cdot \mathbf{s} \cdot(\mathbf{m o l} / \mathbf{k g})^{1 / \mathbf{n}}\right]$} & \multirow{2}{*}{$\boldsymbol{n}[-]$} \\
\cline { 2 - 5 } & $\mathbf{T}=\mathbf{1 9 0}^{\circ} \mathbf{C}$ & $\mathbf{T}=\mathbf{2 3 0}{ }^{\circ} \mathbf{C}$ & $\mathbf{T}=\mathbf{1 9 0}^{\circ} \mathbf{C}$ & $\mathbf{T}=\mathbf{2 3 0}{ }^{\circ} \mathbf{C}$ & \\
\hline LCB-PP & $1.25 \times 10^{-18}$ & $3.79 \times 10^{-19}$ & $4.00 \times 10^{-6}$ & $2.48 \times 10^{-6}$ & 4.049 \\
\hline L-PP & $1.54 \times 10^{-16}$ & $4.81 \times 10^{-17}$ & $4.55 \times 10^{-6}$ & $2.72 \times 10^{-6}$ & 3.620 \\
\hline
\end{tabular}




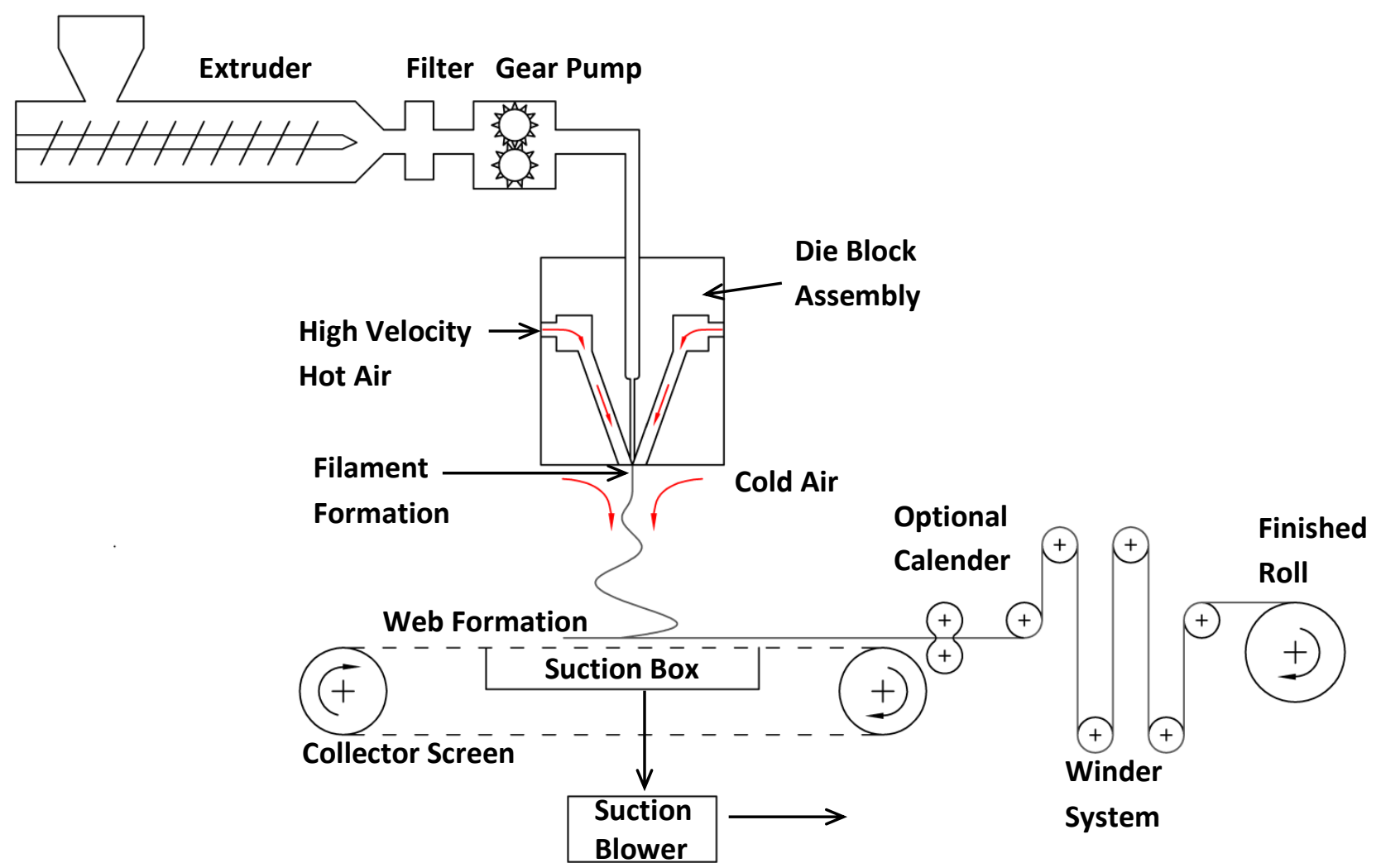

FIGURE 1: Sketch of melt blown line [9, 70]. 

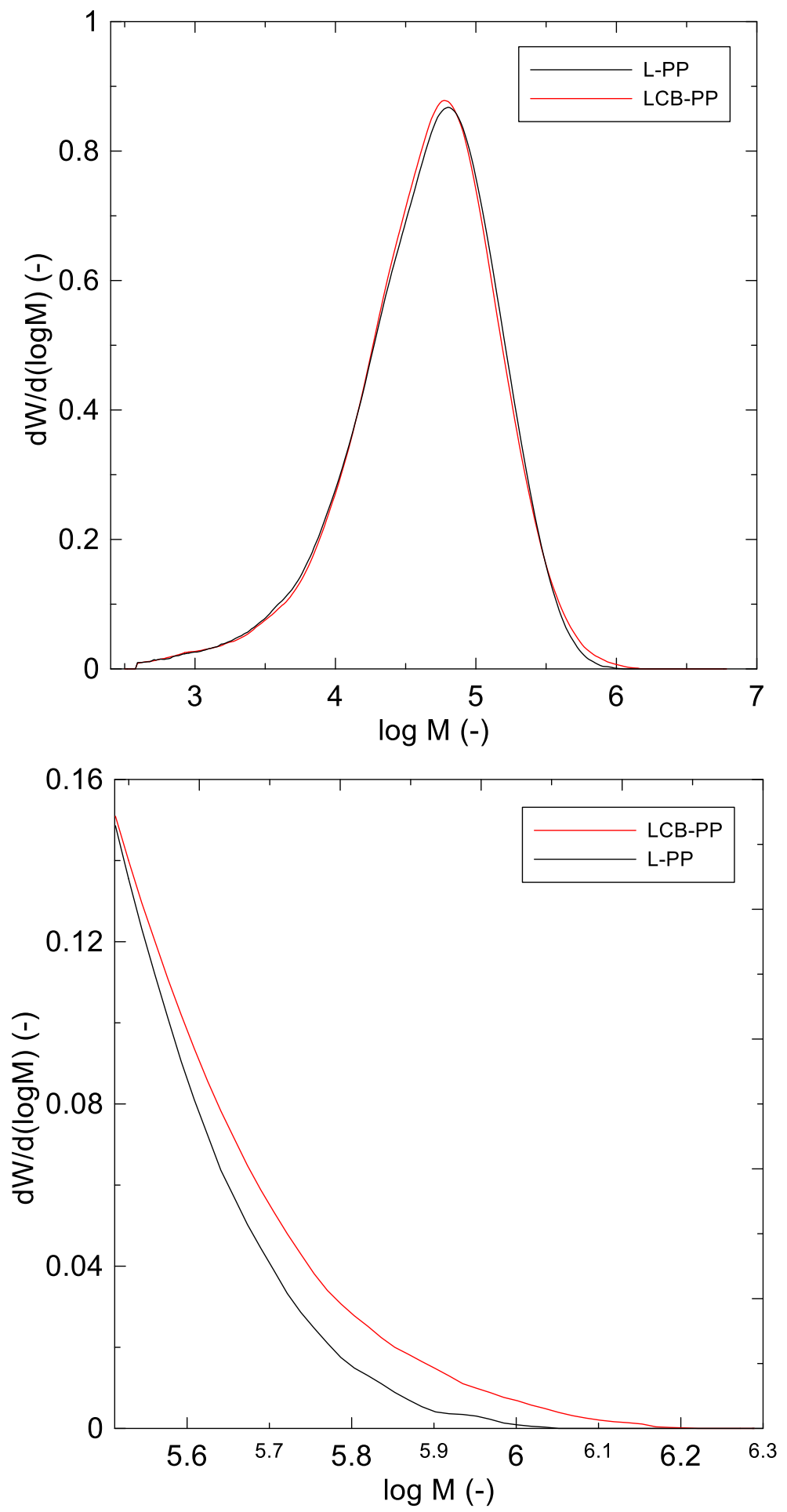

FIGURE 2: Molecular weigth distribution of LCB-PP and L-PP samples (top) with enhanced view for high molecular weight fractions (bottom). 

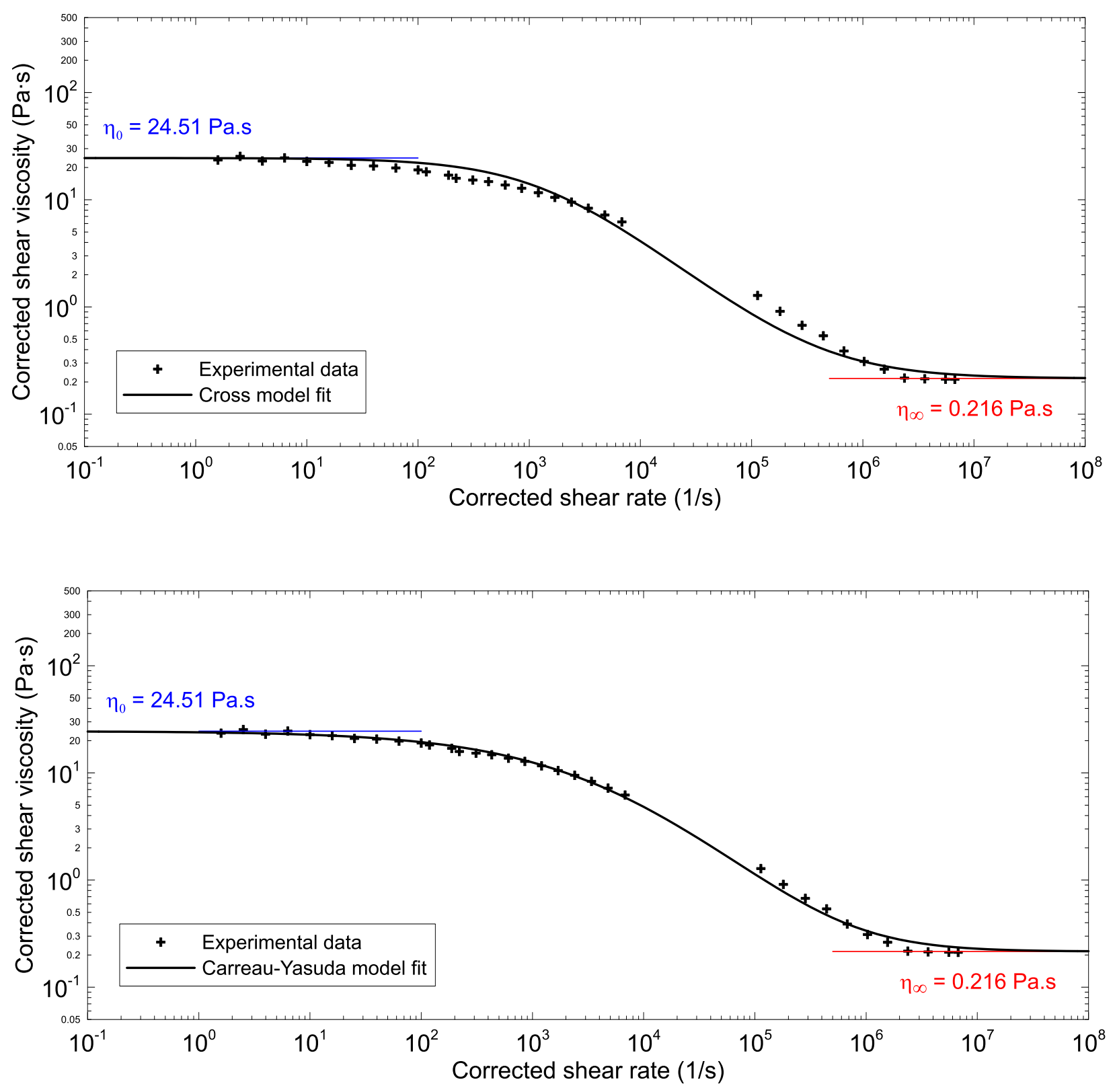

FIGURE 3: Comparison between experimentally determined shear viscosity data and model predictions (Top: Cross model, Bottom: Carreau-Yasuda model) for LCB-PP at $230{ }^{\circ} \mathrm{C}$ and fixed $\eta_{0}$ and $\eta_{\infty}$ parameters. 


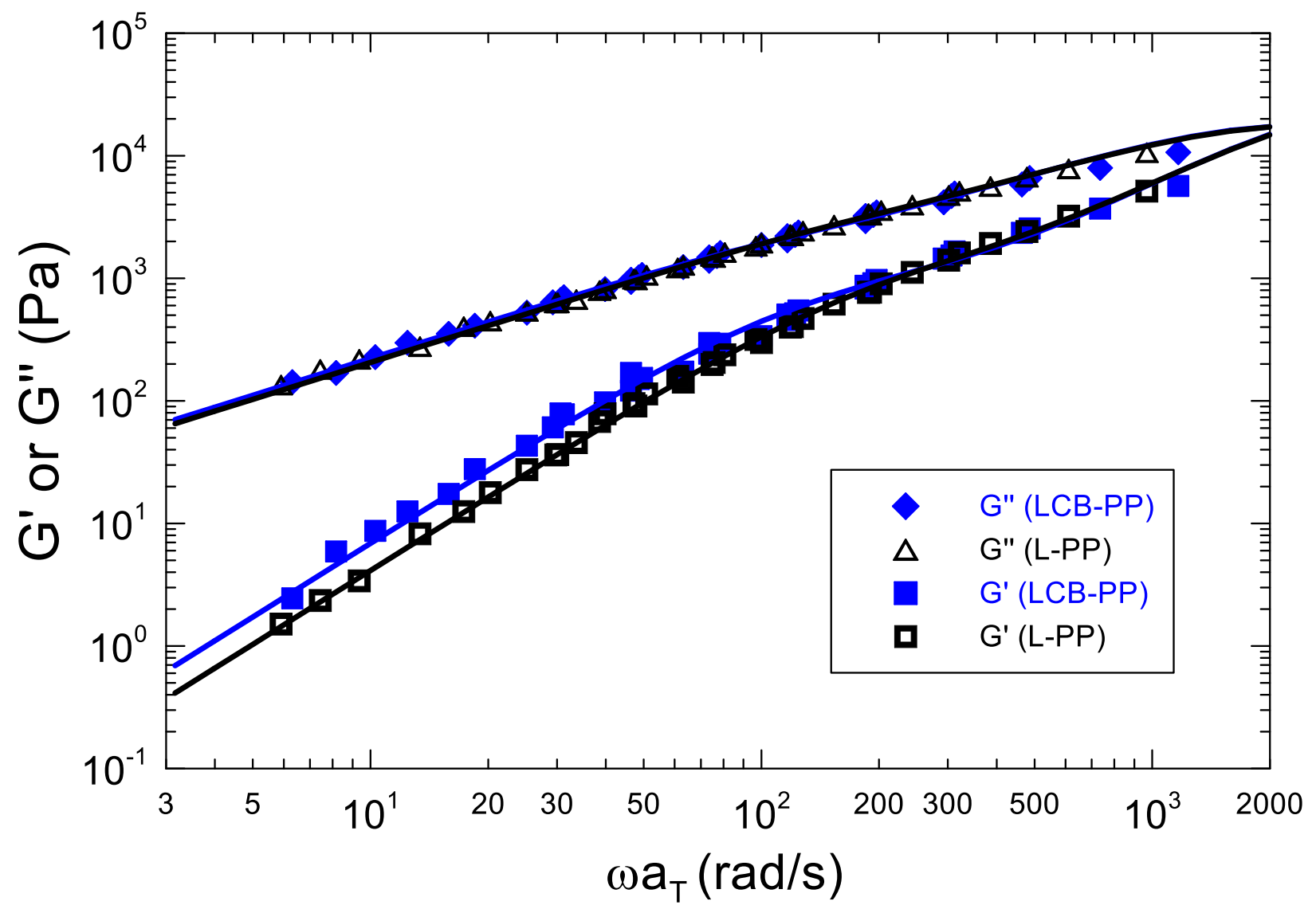

FIGURE 4: Experimentally measured frequency dependent storage, $G$ ', and loss, $G$ " moduli at $230{ }^{\circ} \mathrm{C}$ for L-PP and LCB-PP samples (symbols) fitted by a two-mode Maxwell model (lines). 


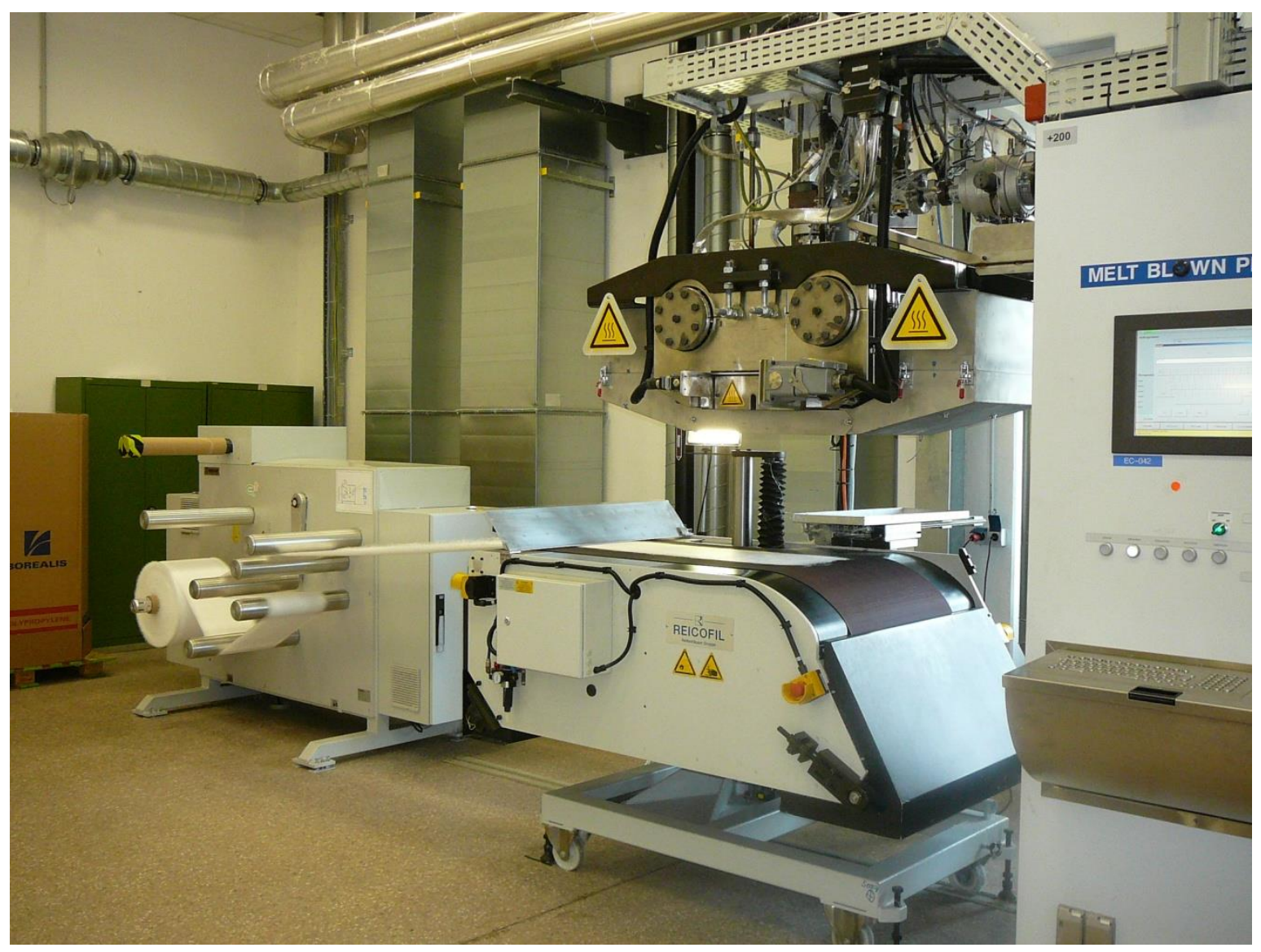

FIGURE 5: Reifenhäuser Reicofil pilot plant melt blown line. 
Magnification: $500 \times$
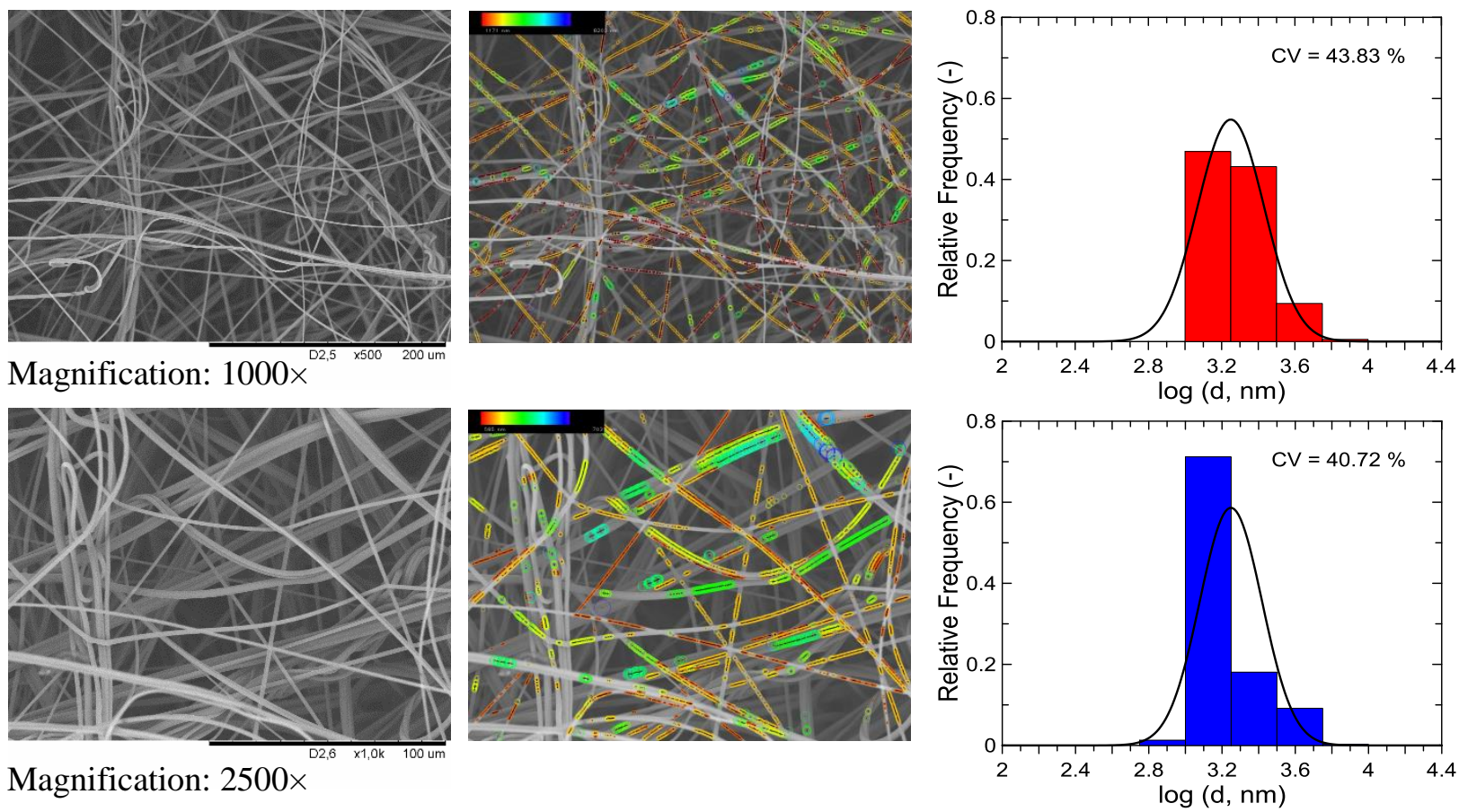

Magnification: 2500x
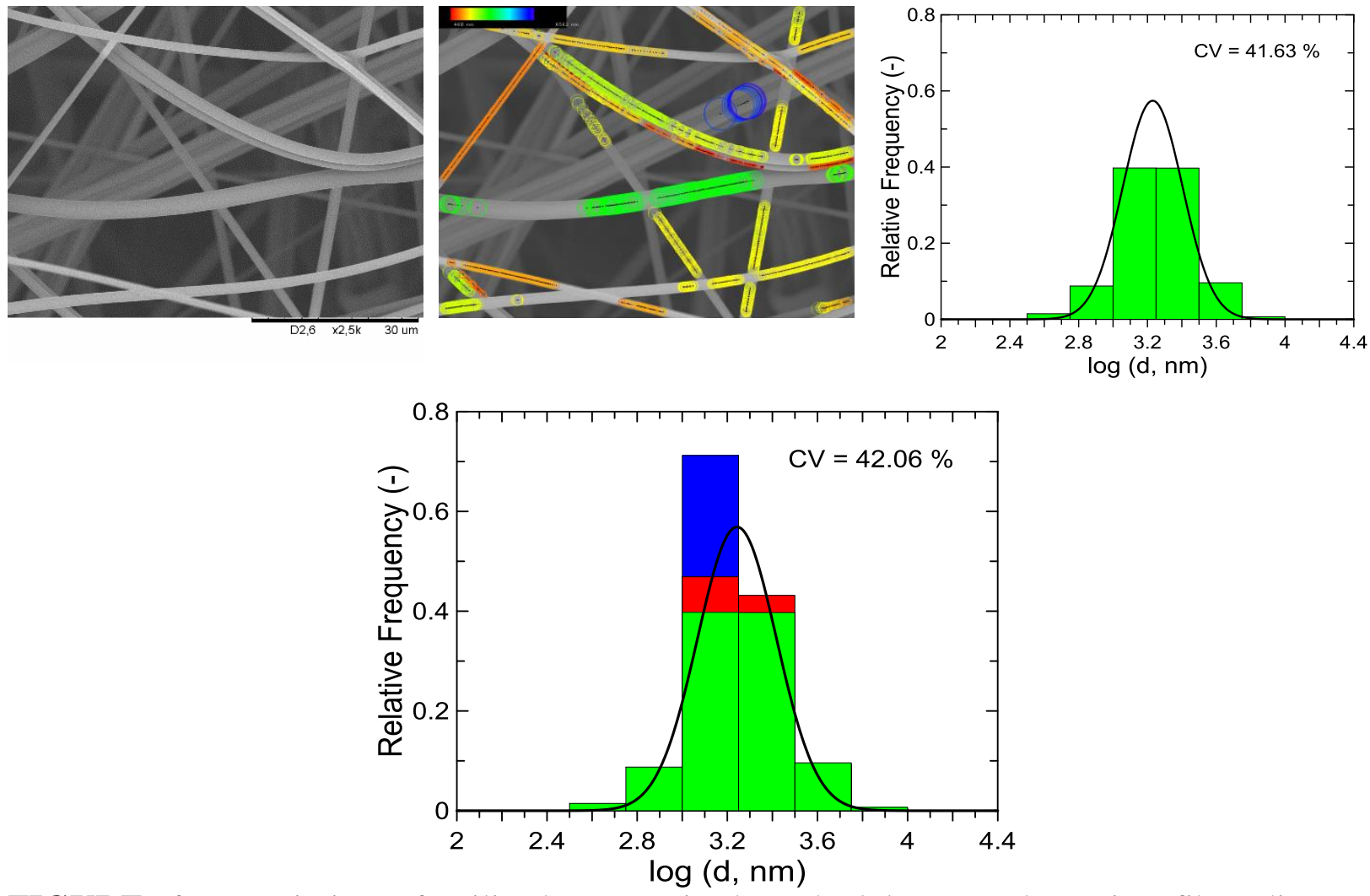

FIGURE 6: Description of utilized automatized methodology to determine fiber diameter distribution for LCB-PP blend $(\mathrm{DCD}=200 \mathrm{~mm})$ at one area and three different magnifications via in-house developed software (UTBsoft); Left - SEM image; Middle - visualization of detected fiber diameters; Right - obtained fiber diameter distribution; Bottom - final overall fiber diameter distribution. 

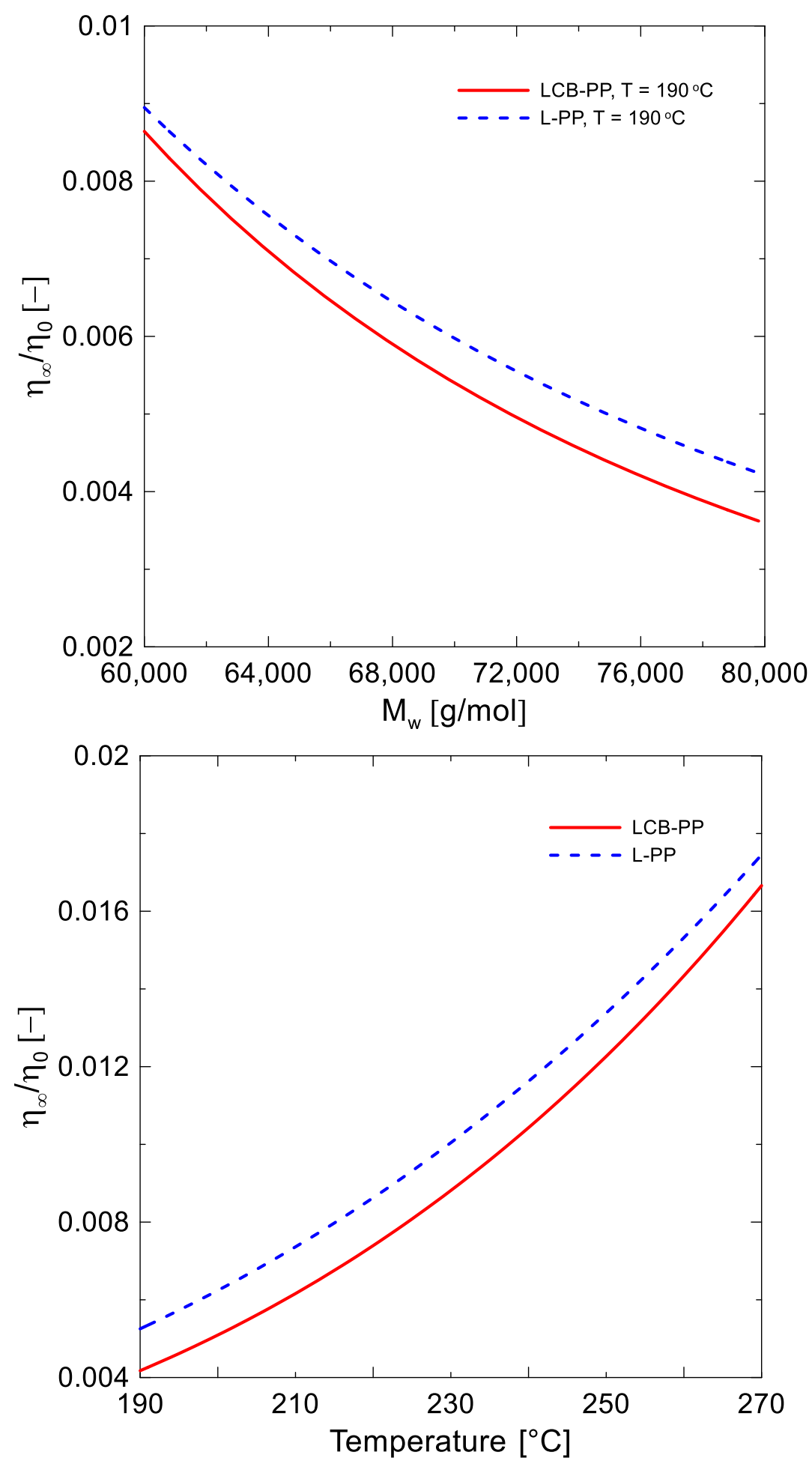

FIGURE 7: Effect of weight average molecular weight (top) and temperature (bottom) on the $\eta_{\infty} / \eta_{0}$ ratio for L-PP and LCB-PP samples predicted according to Eq.19-20 and parameters summarized in Tables 1 and 4. 


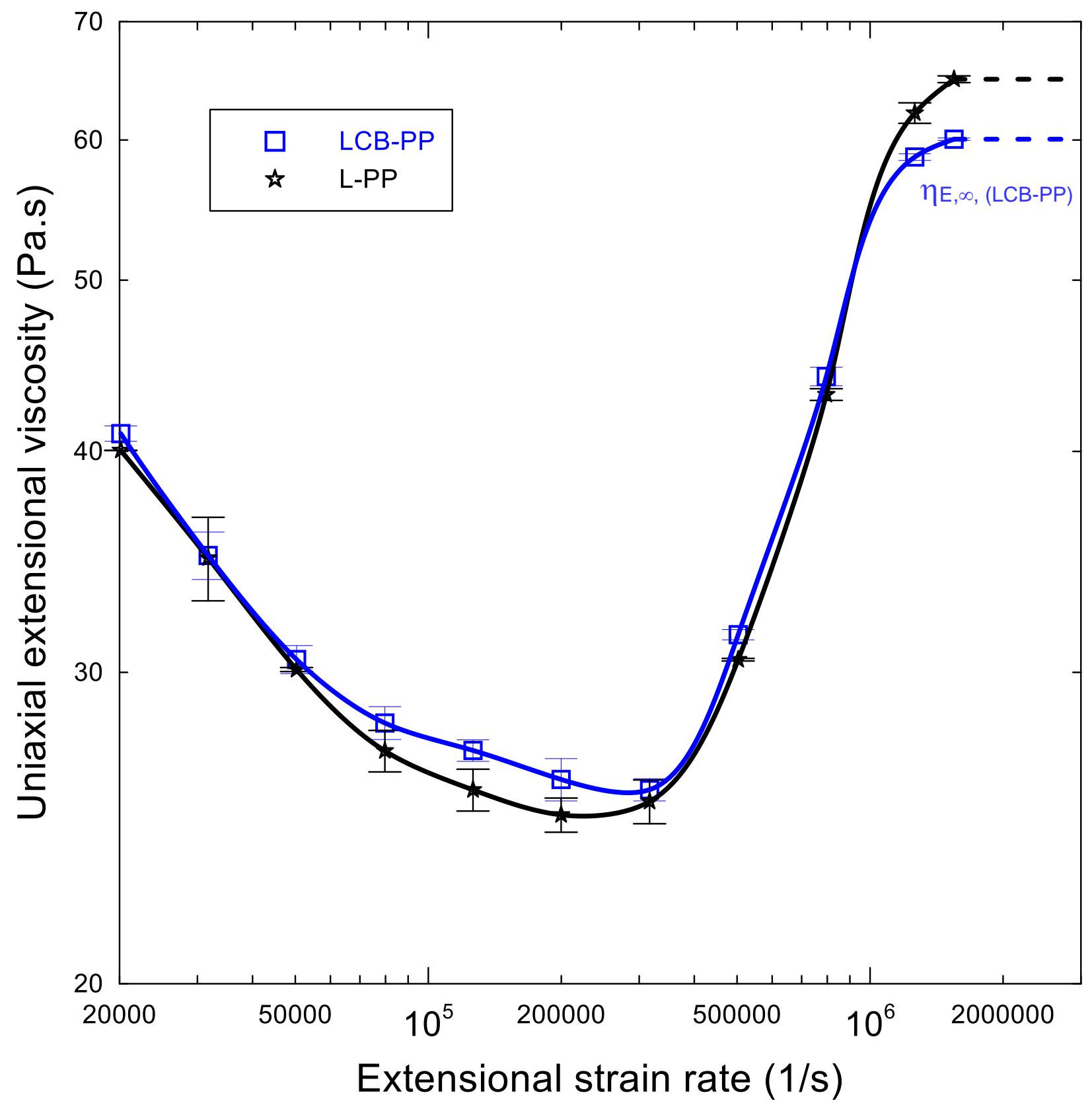

FIGURE 8: Experimentally measured uniaxial extensional viscosity plotted as the function of extensional strain rate for L-PP and LCB-PP samples at $230{ }^{\circ} \mathrm{C}$. 
Area 1
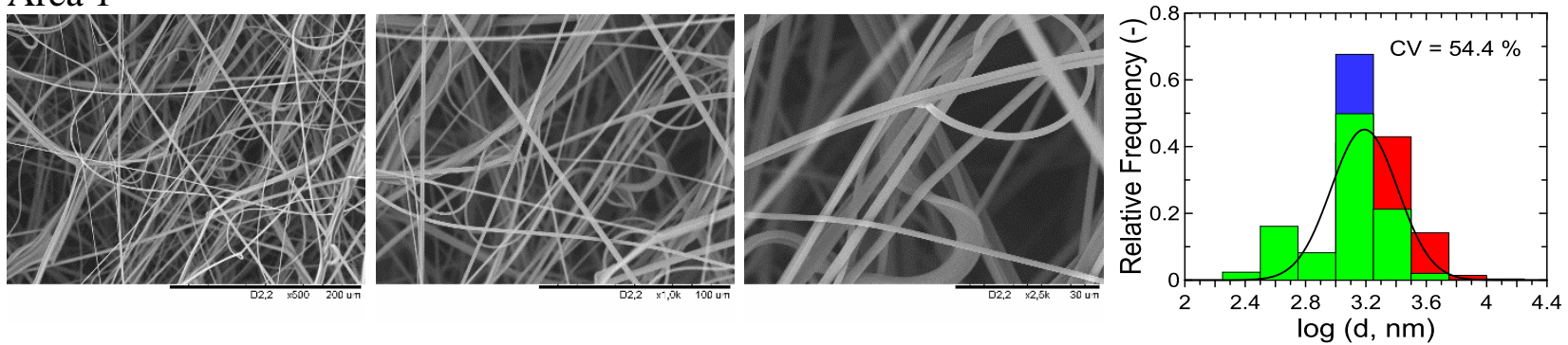

Area 2
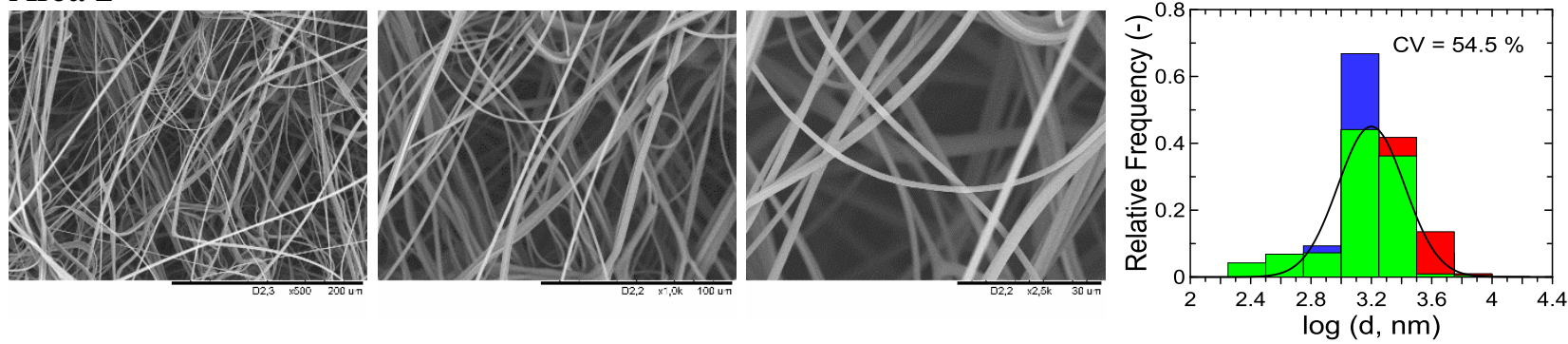

FIGURE 9: SEM images for L-PP sample and DCD $=200 \mathrm{~mm}$ at two different areas and different magnifications (left $-500 \times$, middle $-1000 \times$, right $-2500 \times$ ) together with corresponding final overall fiber diameter distribution.

Area 1
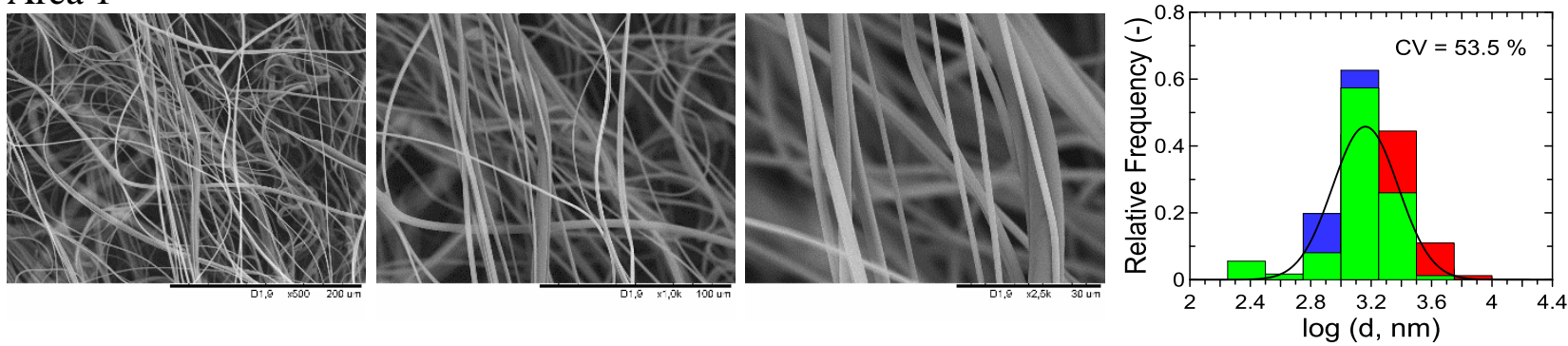

Area 2
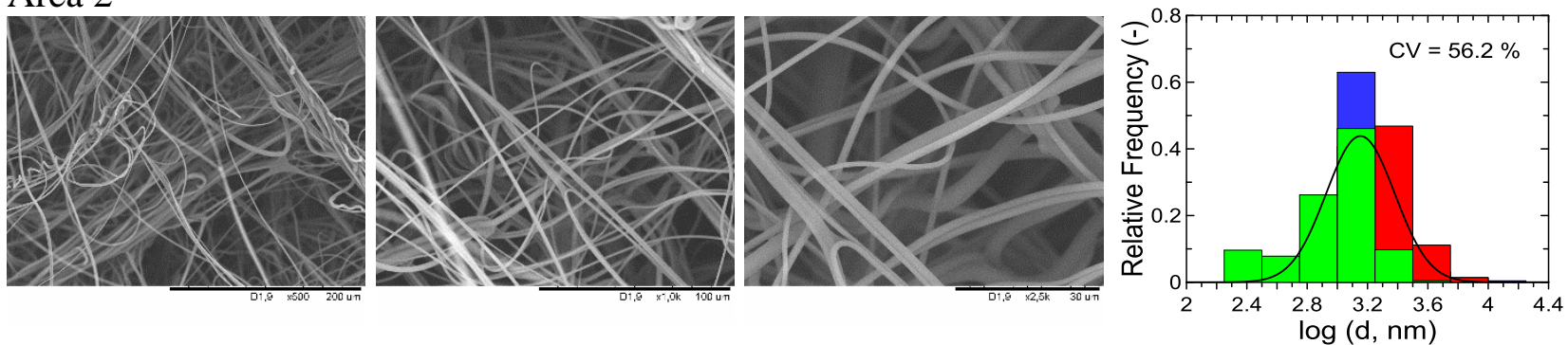

FIGURE 10: SEM images for L-PP sample and DCD $=500 \mathrm{~mm}$ at two different areas and different magnifications (left $-500 \times$, middle $-1000 \times$, right $-2500 \times$ ) together with corresponding final overall fiber diameter distribution. 
Area 1
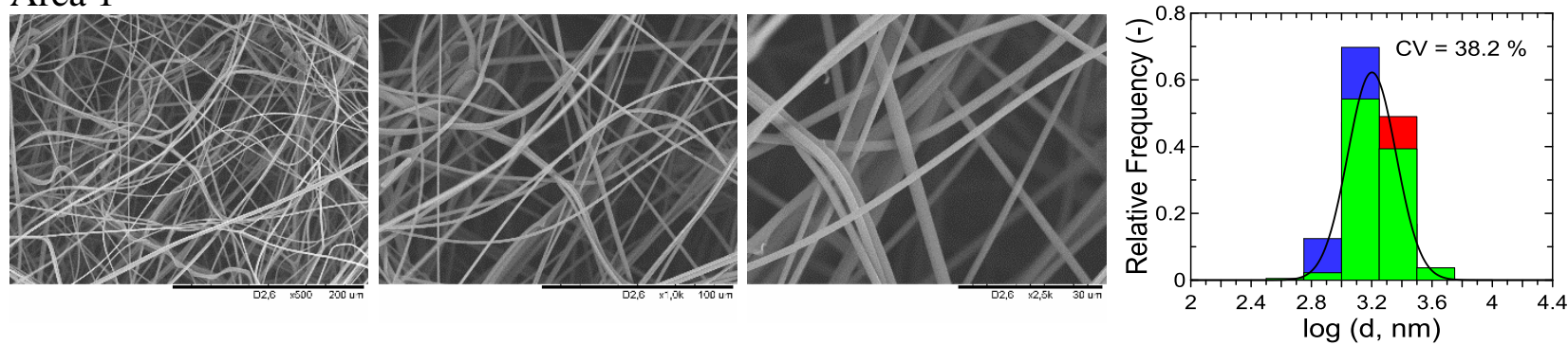

Area 2
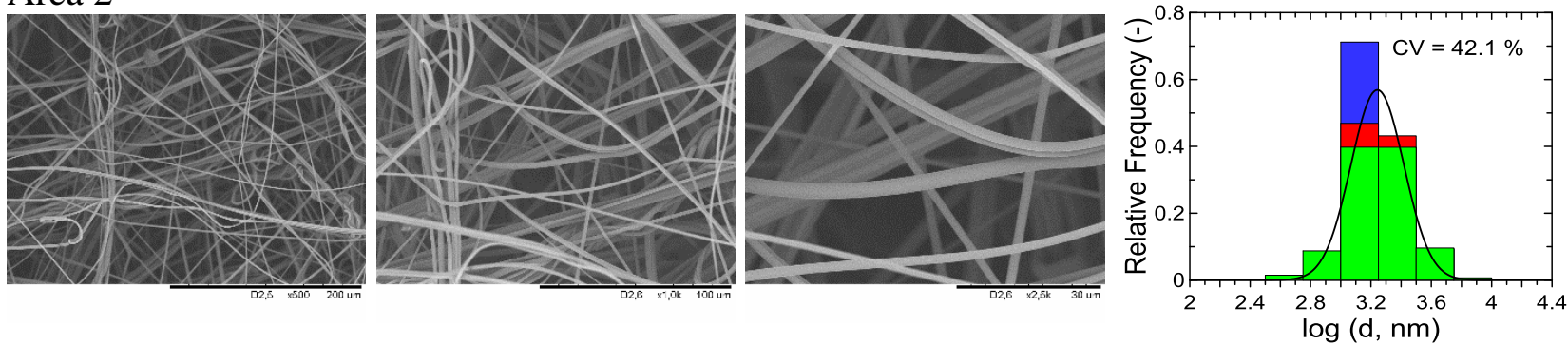

FIGURE 11: SEM images for LCB-PP sample and DCD $=200 \mathrm{~mm}$ at two different areas and different magnifications (left $-500 \times$, middle $-1000 \times$, right $-2500 \times$ ) together with corresponding final overall fiber diameter distribution.

Area 1
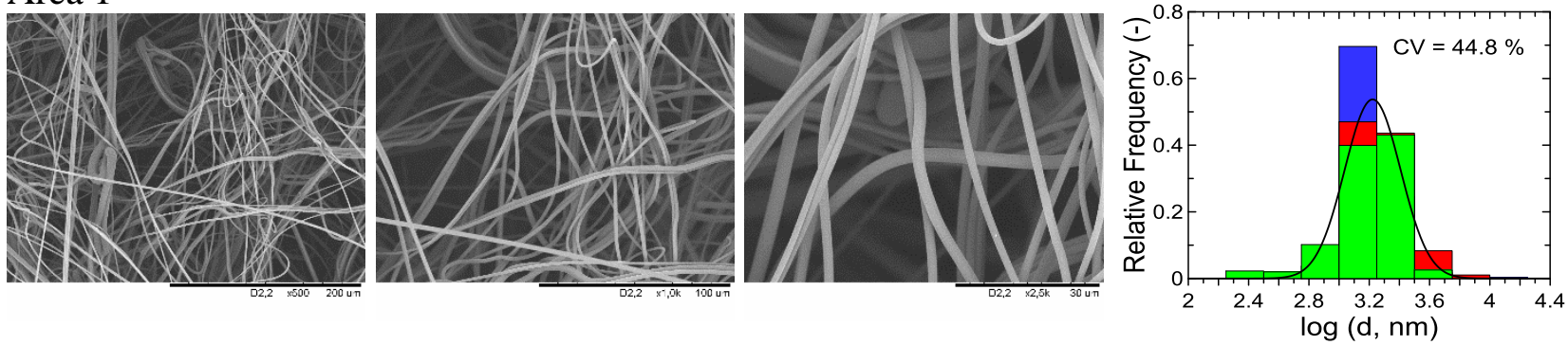

Area 2
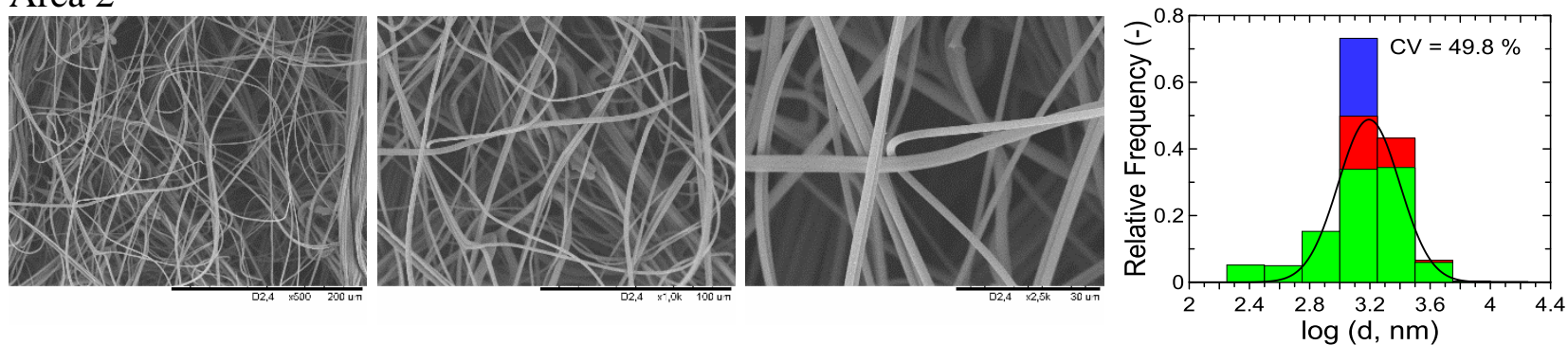

FIGURE 12: SEM images for LCB-PP sample and DCD $=500 \mathrm{~mm}$ at two different areas and different magnifications (left $-500 \times$, middle $-1000 \times$, right $-2500 \times$ ) together with corresponding final overall fiber diameter distribution. 


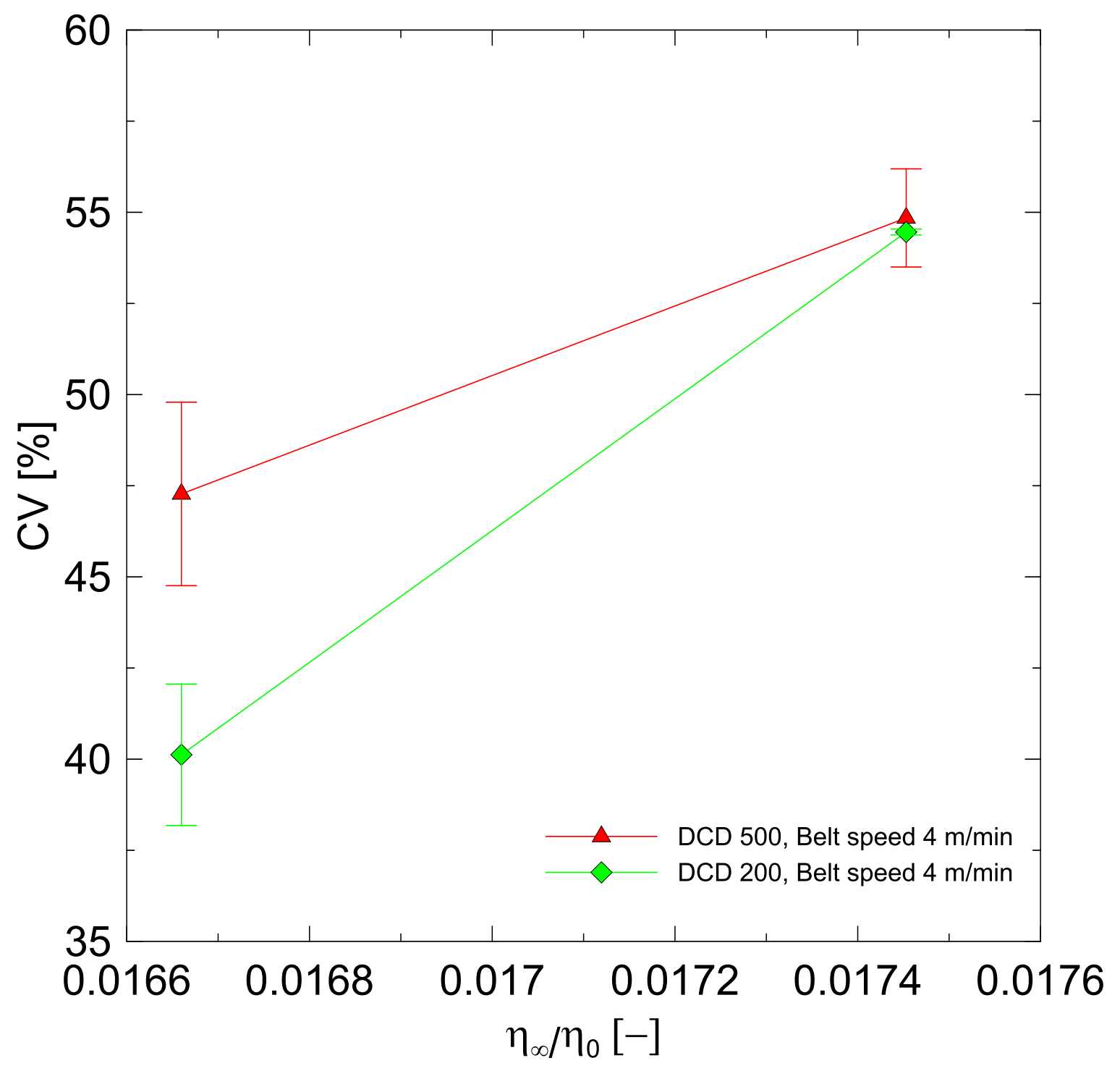

FIGURE 13: Effect of $\eta_{\propto} / \eta_{0}$ on coefficient of fiber diameter variation, $C V$. 


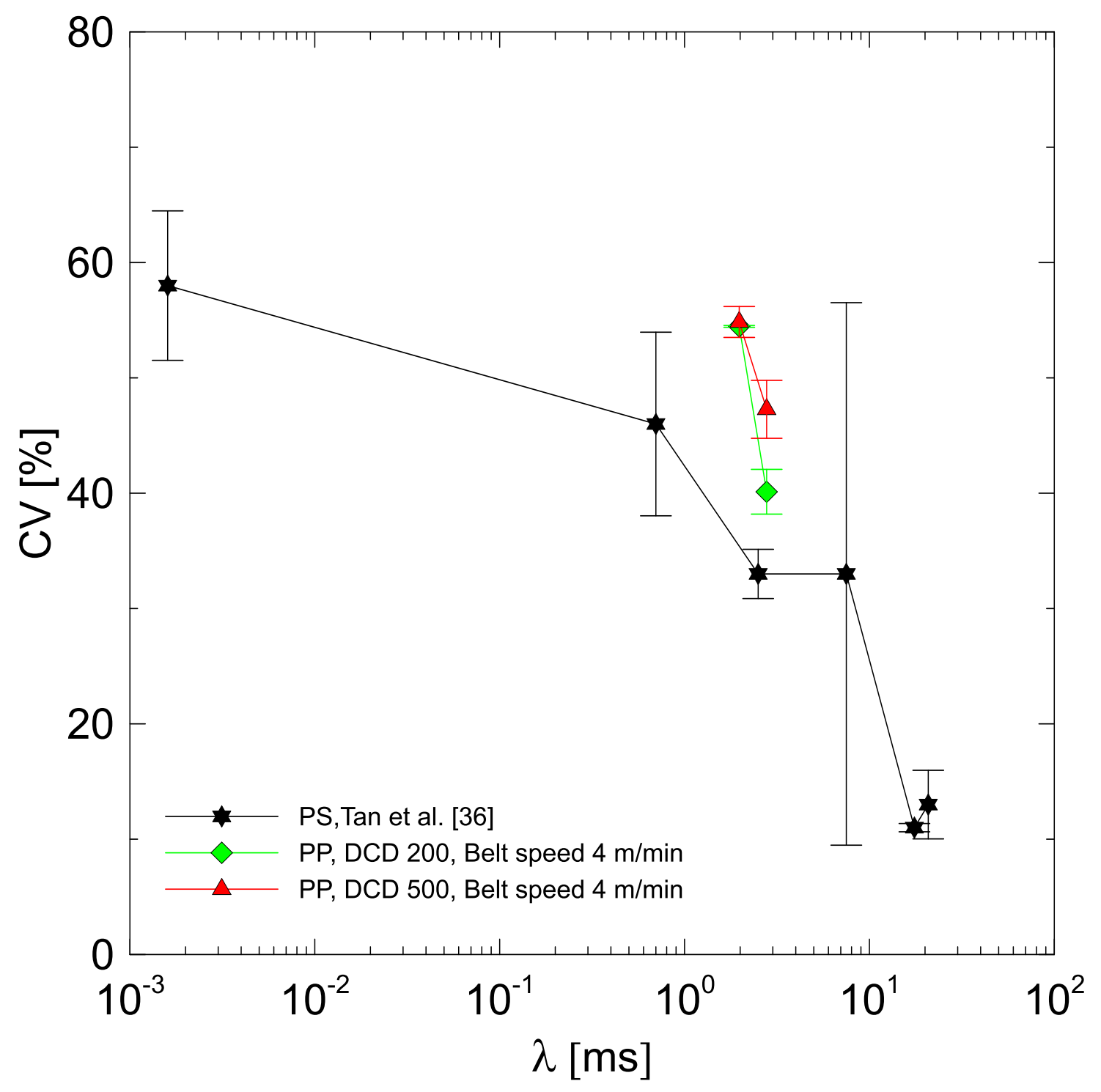

FIGURE 14: Effect of the longest relaxation time on coefficient of fiber diameter variation, CV, for different polymers and processing conditions. 

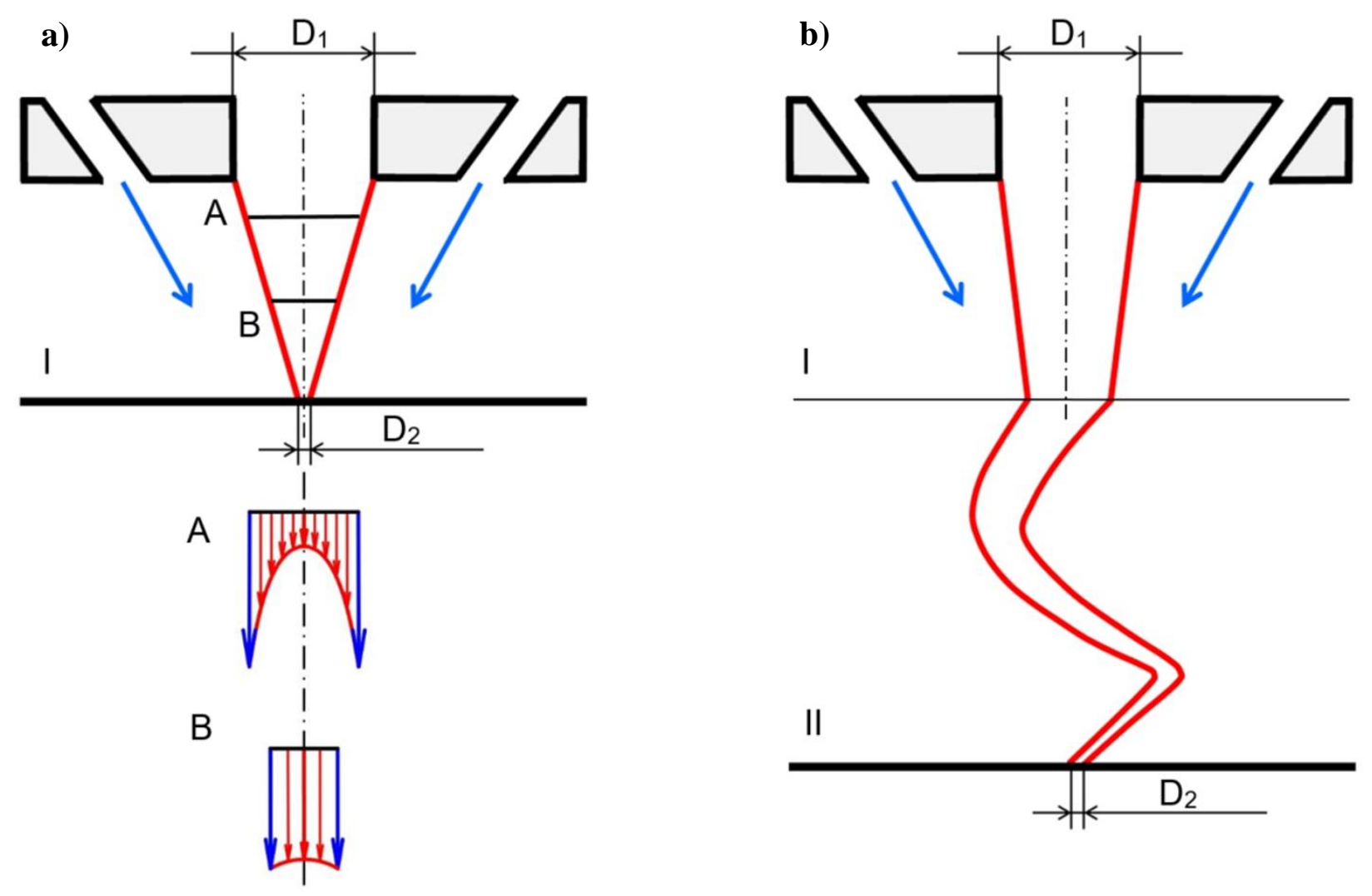

FIGURE 15: Dynamics of fiber attenuation during melt blowing process for two different diecollector distances and two melts with different extensional rheology. In region I the extensional rates are very high (considering to be higher than the reciprocal value of the Rouse time) while in region II, the extensional strain rates are low (considering to be lower than the reciprocal of the Rouse time reaching strain rates comparable to the reciprocal of the reptation time, $\lambda$ ). a) Polymer sample with low infinite extensional viscosity, $\eta_{E, \infty}$, and high extensional viscosity at low strain rates b) Polymer sample with high $\eta_{E, \infty}$ and low extensional viscosity at low strain rates. 